AsClepIo. Revista de Historia de la Medicina y de la Ciencia 69 (1), enero-junio 2017, p169

ISSN-L:0210-4466

http://dx.doi.org/10.3989/asclepio.2017.01

ESTUDIOS / RESEARCH STUDIES

\title{
ARISTÓTELES Y LA MEDICINA
}

\author{
Jordi Crespo Saumell \\ Università degli Studi di Cagliari \\ Email: cresaumell@gmail.com \\ ORCID iD: http://orcid.org/0000-0002-9810-2093
}

Recibido: 19 abril 2016; Aceptado: 18 enero 2017.

Cómo citar este artículo/Citation: Crespo Saumell, Jordi (2017), "Aristóteles y la medicina”, Asclepio, 69 (1): p169. doi: http://dx.doi. org/10.3989/asclepio.2017.01

RESUMEN: En su estado actual el Corpus Aristotelicum no contiene ningún tratado dedicado a la medicina, siendo esto causa suficiente como para que muchos estudiosos hayan dado por hecho que Aristóteles nunca la tomó como objeto de estudio. Otros, empero, pretenden justamente dar pruebas de que Aristóteles sí se interesó por el arte médico, que lo estudió y que es muy plausible que escribiera sobre medicina. Para ello traen a colación razones de diversa índole, aunque básicamente serán dos los argumentos en los que harán hincapié. El primero engloba las analogías médicas que Aristóteles utiliza en sus tratados, y el segundo recurre a las menciones a determinados libros de contenido médico a lo largo del Corpus Aristotelicum. A partir de un examen crítico de ambos argumentos este artículo pretende arrojar algo más de luz sobre el asunto a partir de los contenidos del papiro Anónimo de Londres.

PALABRAS CLAVE: Aristóteles; Medicina; Historia Animalium X; Problếmata; Anonymus Londinensis.

\section{ARISTOTLE AND THE MEDICINE}

ABSTRACT: None of the treatises in the Corpus Aristotelicum is directly concerned to medicine, this leading the majority of scholars to contend that Aristotle did not paid attention to that discipline. But, in other way, there is who argues that Aristotle should have necessarily been acquainted with the principles of the medical art, so that it is very likely that Aristotle enquired on medicine. Almost two different reasons are adduced in this sense: the oft-repeated use of medical analogies in Aristotle's opera, and the allusions to some medical writings by Aristotle himself. In giving a critical description and assessment of both arguments, this paper also aims at clarifying the issue by bringing up into discussion the contents in the Anonymus Londiniensis papyrus.

KEY WORDS: Aristotle; Medicine; Historia animalium X; Problëmata; Anonymus Londiniensis.

Copyright: (C) 2017 CSIC. Este es un artículo de acceso abierto distribuido bajo los términos de la licencia Creative Commons Attribution (CC BY) España 3.0. 


\section{MARCO GENERAL Y PROBLEMÁTICA DEL ESTUDIO DE LA MEDICINA EN ARISTÓTELES}

Figura clave en la historia del pensamiento y de la ciencia, Aristóteles se ocupó prácticamente de todos los ámbitos del conocimiento posibles. Sin embargo, en su estado actual, el Corpus Aristotelicum no contiene ningún tratado dedicado a la medicina. Sabemos que buena parte de las obras de Aristóteles ha desaparecido por completo. En vida Aristóteles fue conocido en los ambientes cultos a través de las obras que publicó, pero no se conserva ninguna de estas obras exotéricas, y con esto, tampoco nada de lo que Aristóteles pudo haber escrito específicamente sobre medicina. El Aristóteles que ha llegado hasta nosotros es el Aristóteles didáctico (Bidez, 1943, p. 43), por lo que tenemos acceso a una versión muy restringida de lo que fue el conjunto de su producción literaria, en particular, solo a aquella que iba dirigida a los estudiantes del Liceo.

El problema que se plantea a la hora de obtener un retrato más o menos fiel de todo sobre lo que Aristóteles pudo tratar - y por ende afirmar si en el Liceo se enseñó la medicina - se ve sin duda acrecentado por la rocambolesca historia del Corpus Aristotelicum. ${ }^{1} \mathrm{~A}$ esto se le tendría que sumar el hecho de que son muy pocas las menciones a médicos que encontramos en el Corpus, como si Aristóteles hubiera considerado que eso no era relevante, pues, por lo general habla de los médicos como de un colectivo, sin llegar casi nunca a individualizar. ${ }^{2}$ Estos detalles de partida son causas suficientes como para que muchos estudiosos hayan dado por hecho que Aristóteles nunca tomó la medicina como objeto de estudio, y si nos atenemos a dichas dificultades, lo cierto es que están en todo su pleno derecho. ${ }^{3}$

Con esto en mente mi intención es aportar argumentos para todo lo contrario, señalar las razones de diversa índole - aunque a tenor de lo dicho sobre todo textuales - por las que cabe hablar de un lugar para la medicina en la filosofía de Aristóteles, y a partir de estas reconstruir dentro de lo posible cuales pudieron haber sido los fundamentos de la medicina aristótelica.

\section{ASPECTOS SOCIOLÓGICOS DE LA MEDICINA EN LA ÉPOCA DE ARISTÓTELES}

Alcmeón de Crotona ${ }^{4}$, Empédocles ${ }^{5}$, Demócrito ${ }^{6}$, Diógenes de Apolonia ${ }^{7}$, Anaxágoras ${ }^{8}$, Parménides, Pitágoras, Filolao...la mayoría de los fisiólogos ${ }^{9}$ presocráticos o bien fueron médicos o trataron en alguna medida aspectos tales como la constitución y el fun- cionamiento del cuerpo, las enfermedades del alma, la embriología, la nutrición, la respiración, el pulso, la fiebre o los principios de la enfermedad. Más tarde también lo hicieron Platón, Teofrasto, Estratón o Sexto Empírico. En el De sensu et sensato Aristóteles dice que no es nada raro que los filósofos terminen sus libros con una discusión sobre medicina, y que los médicos empiecen los suyos debatiendo ciertos principios filosóficos. ${ }^{10}$ Parece por tanto difícil imaginar que Aristóteles, buen conocedor como era de toda la tradición filosófica anterior ${ }^{11}$, no hubiera dado ningún paso en este sentido.

Al margen de esto, una tal despreocupación por la medicina por parte de Aristóteles resulta aún mucho más inverosímil si se tienen en cuenta las implicaciones sociológicas de la medicina en la antigua Grecia (Nutton, 1995, p. 18). Aristóteles, como Hipócrates, era de estirpe Asclepiade, tanto por parte de padre como de madre (Nutton, 2004, pp. 69, 118; Manetti, 2014, p. 232). ${ }^{12}$ Entre los Asclepiadas los entresijos de la disección y de las otras técnicas vinculadas al arte de la medicina se transmitían de generación en generación (Boudon, 1994, pp. 1423; Longrigg, 1995, p. 431). ${ }^{13}$ Nicómaco, el padre de Aristóteles, fue un famoso médico cirujano que se ocupó, en primer lugar, de la salud del rey Amintas II de Macedonia ${ }^{14}$ y luego de la del hijo de este, Filipo (el que fuera padre de Alejandro Magno cuyo tutor por algún tiempo fue el propio Aristóteles). ${ }^{15}$ La hija de Aristóteles, Pitia, se casó con Metrodoro, el médico alejandrino maestro de Erasístrato de Quíos (Wilson, 1959, p. 297; Viano, 1984, p. 310). ${ }^{16}$ Por este motivo es casi seguro que Aristóteles conocía los principios del arte de la medicina (Marenghi, 1961, pp. 147-148). ${ }^{17}$

En la Antigüedad existió, además, una educación médica de corte exclusivamente teórico. ${ }^{18}$ La formación de una persona cultivada requería de una cierta familiaridad con la cultura médica, familiaridad que quedaba al margen de toda pretensión profesional ${ }^{19}$, por lo que cuesta creer que Aristóteles pudiera haberse sustraído también a la tendencia pedagógica imperante de su tiempo. En relación a esto, quizás parte de la raíz del asunto esté en el hecho de que el término 'médico' (iatrós) era polisémico en griego. ${ }^{20}$ En la Política ${ }^{21}$ Aristóteles afirma que la palabra 'médico' cuenta por lo menos con tres significados distintos: el que se aplica a quien practica el arte médico, el que se dice de quien ha adquirido un alto nivel de conocimiento en el arte médico ${ }^{22}$, y en tercer lugar, y más importante aquí, el que se emplea para hacer referencia a la persona instruida en los 
principios de la medicina. ${ }^{23}$ En la época clásica, por tanto, y más en concreto en Aristóteles, el iatros pepaideuménos (Eijk van der, 1995, p. 452) era quien en pro de su educación (Jaeger, 1945, pp. 3, 24-25) ${ }^{24}$ se interesaba por la medicina y sus principios, sin que esto significara que necesariamente la practicase (Lloyd, 2003, p. 178). ${ }^{25}$

\section{LOS TRATADOS MÉDICOS DE ARISTÓTELES}

Se han expuesto hasta aquí, sumariamente, las razones contextuales por las que es más que plausible que Aristóteles pudiera haber tratado de temas médicos. Para dar más firmeza todavía a esta suposición se examinará ahora qué es lo que en este sentido podemos hallar en los textos de Aristóteles.

De entrada, deben tenerse en cuenta las numerosas ocasiones en las que, para explicar mejor la idea que está exponiendo, Aristóteles pone la medicina como ejemplo o la usa como analogía (Eijk van der, 2005, p. 264 n. 23; Eijk van der y Francis, 2009, p. 221). ${ }^{26}$ El empleo de la analogía responde a la necesidad de dar un mayor grado de verosimilitud explicativa a los fenómenos descritos cuando estos se basan en una mera posibilidad teórica, o en un argumento inobservable. La analogía refleja por parte de quien la usa el conocimiento tácito de los elementos implícitos que posibilitan la misma, y en lo que aquí concierne, el conocimiento de los procedimientos del arte de la medicina por parte de Aristóteles. El problema está en discernir entonces si Aristóteles usó dichas analogías solo en el plano retórico o si, de lo contrario, estas implican que en algún modo la medicina se enseñó y se practicó en el Liceo. ${ }^{27}$ Contra esto podría objetarse, claro está, que todos los ejemplos de analogías médicas a los que Aristóteles recurre hacían parte del acervo común de conocimiento al alcance de cualquier griego y que, por consiguiente, no pueden constituir ninguna prueba fehaciente de que Aristóteles hubiera cultivado un particular saber de tipo médico.

El hecho es que, si se quiere, entre los tratados de Aristóteles tampoco faltan menciones a la medicina de un calado mucho más técnico. Son cuatro, concretamente, los casos a estudiar en lo que a esto se refiere. En primer lugar las numerosas referencias, unas veinte, que Aristóteles hace a un tratado llamado Disecciones; en segundo lugar, las diversas menciones a otro escrito que lleva por título Sobre la enfermedad y la salud; en tercer lugar, el contenido del último libro de la Historia Animalium y, finalmente, la colección de cuestiones médicas tratadas en los Problemas.

\subsection{Las Disecciones}

De acuerdo con el testimonio de Galeno ${ }^{28}$, el primero en escribir un tratado sobre anatomía fue Diocles de Caristo. Dados sus vínculos con el Liceo (Kudlien, 1963, pp. 459-460), algunos expertos creen que las menciones que Aristóteles hace al tratado de las Disecciones $^{29}$ se refieren a la obra de Diocles titulada De anatomia animalis, en la que Aristóteles se habría inspirado para escribir su propio tratado homónimo (Byl, 2011b, p. 118). Contamos no obstante con algunos indicios que nos permiten afirmar diferencias sustanciales entre uno y otro, por ejemplo, en el modo como explicaron que tenía lugar la alimentación de los mamíferos en el útero (Viano, 1984, p. 313); por lo que podemos pensar que Aristóteles desarrolló una actividad en este campo ${ }^{30}$ con independencia de las observaciones de Diocles.

Debemos suponer entonces que entre las páginas de sus diversos tratados sobre zoología ${ }^{31}$, así como también entre las de los Parva Naturalia ${ }^{32}$, Aristóteles hace alusión a una obra "suya" titulada Disecciones (Giannantoni, 1984, p. 66; Eijk van der, 2005, p. 263; Byl, 2011b, p. 119). Asimismo, a la luz de lo que se puede leer en sus tratados de biología parece que Aristóteles y sus discípulos ${ }^{33}$ diseccionaron diferentes tipos de animales a fin de obtener un conocimiento más amplio del mundo natural y de procesos tales como el envejecimiento, el sueño, el movimiento o la percepción. Aristóteles realizó disecciones sistemáticas de al menos 50 especies de animales. ${ }^{34}$ Dividido en siete libros, el tratado de las Disecciones debió consistir en un manual con esquemas, modelos, dibujos y figuras de animales diseccionados ${ }^{35}$ después de que estos murieran por enfermedad, o que el mismo Aristóteles sacrificó mediante un procedimiento especial por asfixia (Wilson, 1959, p. 294; Viano, 1984, pp. 317, 334). ${ }^{36}$ Parece claro que Aristóteles diseccionó animales con el fin de confeccionar tablas anatómicas (Longrigg, 1993, pp. 164, 172), y que gracias a ello pudo ahondar en el comportamiento animal, saber qué partes se regeneraban y cuáles no, y por la misma razón, qué partes eran imprescindibles para la supervivencia de un animal. Las Disecciones corresponderían al deseo de Aristóteles de clasificar las doxografías, los resúmenes y las enseñanzas sobre este asunto, así como al de recoger los materiales y los dibujos realizados durante las operaciones anatómicas (anatomaí) que tenían lugar en las lecciones de anatomía y de fisiología del Liceo (Marenghi, 1961, p. 150).

Otra cosa distinta es afirmar, como han hecho algunos, que Aristóteles también diseccionó fetos humanos abortados. Mis reservas ante esta opinión las 
suscitan, en primer lugar, el pudor y el respeto sacrílego que los griegos de la época clásica sentían hacia el cadáver humano; pero aparte de esta razón de tipo antropológico-religioso también, y nada menos, tanto los prejuicios metodológicos del propio Aristóteles como el estadio de desarrollo de la ciencia experimental en la Atenas de los ss. IV-III a.C. Así, algunos errores que encontramos en ciertos tratados del Corpus Aristotelicum invitan a pensar que Aristóteles rechazó todo tipo de experimentación. Aristóteles estaba convencido de que la creación de condiciones artificiales ponía los acontecimientos fuera de su marco general, y que eso desnaturalizaba los fenómenos. ${ }^{37}$ Además, un empeño experimental de este tipo entraría en contradicción con el carácter meramente teorético de la medicina en la paideía griega. Las disecciones y los estudios anatómicos del interior del cuerpo humano por parte de los médicos obedecieron a razones absolutamente prácticas, a saber, la necesidad de curar las heridas, la ortopedia, y la ginecología-obstetricia (Viano, 1984, p. 318).

En lo que concierne a los logros científicos en el tiempo de Aristóteles, historiadores de la ciencia como B. Russell o M. Grmek han negado cualquier forma sistemática de experimentación en la Grecia clásica (Staden von, 1975, pp. 178-180; Grmek, 1997, p. 19). En lo que a la experimentación anatómica se refiere, parece que la práctica de la disección del cuerpo humano solo tuvo lugar durante un breve periodo, reduciéndose esta además a la ciudad de Alejandría (Lloyd, 2003, p. 203). ${ }^{38}$ Por todo esto parece más plausible que Aristóteles hubiera procedido por analogía, por inferencia y por comparación ${ }^{39}$ en base a las observaciones obtenidas a partir de la disección de animales (Bidez y Leboucq, 1944, p. 34; Giannantoni, 1984, p. 67; Viano, 1984, p. 321; Longrigg, 1993, p. 161).

\subsection{El tratado Sobre la enfermedad y la salud}

En diversos pasajes de sus escritos Aristóteles manifiesta la intención de compilar el saber médico y de escribir a propósito de la medicina ${ }^{40}$; como resultado de dicho empeño habría pergeñado un supuesto tratado titulado Sobre la enfermedad y la salud. ${ }^{41}$ De entrada las opiniones al respecto son encontradas. Hay quienes sostienen, como E. Zeller, que se trata solo de un desideratum que Aristóteles nunca llevó a cabo (Zeller, 1879, p. 96) mientras que otros, como E. Heitz, creen que el Sobre la enfermedad y la salud debe tenerse como una obra en toda regla que hacía parte de los Parva Naturalia (Heitz, 1865, pp. 56-58). De este modo, hay quienes opinan que los comentarios al fi- nal del De respiratione ${ }^{42}$ pertenecieron al Sobre la enfermedad y la salud (Manetti, 1989, p. 350). Si hubiera que tomar parte en el asunto habría que decir que son más los indicios que apuntan hacia lo segundo que hacia lo primero puesto que Alejandro de Afrodisia ${ }^{43} \mathrm{da}$ testimonio de un tratado con ese título.

\subsection{El libro $X$ de la Historia animalium}

En los dos subcapítulos precedentes se han visto dos tratados de temática médica que según las fuentes parece que Aristóteles escribió pero de los que, aparte de que desaparecieron, poco más se puede decir. El tercer caso que ahora se analiza es algo distinto.

El libro $\mathrm{X}$ de la Historia animalium lleva por título Sobre la esterilidad ${ }^{44}$ y tiene por objetivo la investigación de las causas de la infertilidad humana: por qué las mujeres a veces no consiguen engendrar $y$, en el caso de que las haya, cuáles son las formas para paliar dicha incapacidad. ${ }^{45}$ En el s. III d.C. Diógenes Laercio da fe de la existencia de un libro llamado Sobre la esterilidad (Eijk van der, 2005, p. 263). Este dato se muestra revelador si se repara en el hecho de que en dos de los catálogos de las obras de Aristóteles se dice que la Historia animalium consta de 9 libros (Eijk van der, 2005, pp. 274-275) ${ }^{46}$, y no de 10 según su actual disposición. Además existe un grupo de manuscritos medievales de la Historia animalium que no tiene en cuenta el libro X (Berger, 2005, pp. 59-65). ${ }^{47}$ Estos son algunos de los motivos por los que este podría haber constituido una unidad per se, un tratado concebido y escrito separadamente que acabó añadido a los 9 libros precedentes de la Historia animalium. ${ }^{48}$

La cuestión se centra ahora en averiguar si cabe atribuir el tratado Sobre la esterilidad a Aristóteles o no. Son los detalles de tipo argumentativo, práctico y técnico expuestos a lo largo de este libro los que básicamente inducen a creer que Aristóteles no pudo haberlo escrito. En primer lugar porque el autor no argumenta de acuerdo con los patrones, esquemas y conceptos típicamente aristotélicos (Eijk van der, 2005, p. 261). En segundo lugar porque se pone de manifiesto un notable conocimiento empírico por parte de su autor con las situaciones que requieren de tratamiento (therapeías deĩtai), así como un conocimiento de lo que se puede tratar y de lo que no se debe tratar en tanto que irreversible (iatòn kaì aníaton)..$^{49}$ En tercer lugar porque el lenguaje y el contenido de los fenómenos descritos en el libro $\mathrm{X}$ implican la observación directa de determinadas afecciones ${ }^{50}$ y la práctica de técnicas médicas específicas, como por ejemplo, el reconocimiento de la paciente por vía del tacto ${ }^{51}$. Por último, las críticas que 
supuestamente Aristóteles dirige a sus "colegas de profesión" a la hora de diagnosticar ciertos quistes (mýlas) en el útero ${ }^{52}$ dan a entender que el libro $X$ no es de Aristóteles. Es pues en base a razones de este género que los expertos creen que lo que se expone en el libro $X$ de la Historia animalium es impropio de Aristóteles y, por ende, que no es de suyo adjudicárselo. ${ }^{53}$

\subsection{Los Problếmata physiká}

Pese a que Cicerón, Galeno o Plutarco afirmen que escribió un libro sobre problemas, no hay duda de que Aristóteles no fue el autor de los Problemas. De hecho, tal y como sucede con el tratado titulado De spiritu, a menudo las ediciones modernas se refieren al autor de los Problemas como 'pseudo-Aristóteles'. En su versión actual, los contenidos de esta colección se escribieron con posterioridad a la muerte del filósofo, compilándose e implementándose en fases sucesivas desde la segunda mitad del s. III a.C. hasta bien entrado el s. V d.C. ${ }^{54}$ No puede negarse, sin embargo, que los Problémata son producto de la investigación por parte de miembros del perípato, o muy afines al aristotelismo (Moraux, 1951, p. 116). Son características de cuño claramente aristotélico tanto el modo en que se abordan los problemas y se formulan las preguntas como el modo de buscar soluciones a los problemas planteados (Marenghi, 1965, pp. XV-XVI).

El vasto material recogido a través de un tal lapso de tiempo trata, por lo general, de cuestiones relacionadas con la fisiopatología: problemas generales de patogénesis, terapéutica, los efectos de la posición del cuerpo, la influencia del clima, la fisiopatología de los órganos de los sentidos y también de problemas relacionados con la piel. Especialmente relevante es la definición de 'fármaco' que encontramos en el libro I de los Problémata: un fármaco es algo que no es un alimento, es decir, una sustancia que cuando penetra en los vasos de los intestinos provoca alteraciones en el cuerpo pero que no viene ni digerida ni asimilada por este, aunque se ingiera en mínima cantidad, pues un fármaco por definición resiste al calor natural del cuerpo. ${ }^{55}$ Igualmente, y puesto que implican que "Hipócrates" fue sin duda conocido y estudiado en el Liceo (Marenghi, 1965, p. XVI) ${ }^{56}$, el libro I de los Problếmata Physiká es también valioso por sus numerosas alusiones al tratado Aires, aguas y lugares y a los Aforismos.

\section{LOS IATRIKÁ DE ARISTÓTELES Y EL PAPIRO ANÓNIMO DE LONDRES}

Aunque escasas, son varias las referencias a una obra médica de Aristóteles en dos libros titulada la- triká (De medicina) ${ }^{57}$; aunque es la mención que Galeno hace a la misma ${ }^{58}$ la que sentará precedentes y será asumida por toda la tradición posterior. En su comentario al De natura hominis Galeno escribe: quienquiera informarse bien sobre las opiniones de los antiguos sobre esta cuestión (sc. las causas de la enfermedad) debe leer el latrikè synagōgé ${ }^{59}$ que, pese estar atribuido a Aristóteles, fue escrito por su discípulo Menón. Debido a este inciso los latriká se conocerán también con el sobrenombre de Menonia o Menoneia. ${ }^{60}$ Como se ha visto ${ }^{61}$, esto encaja bien con el proyecto enciclopédico que Aristóteles tenía en mente, puesto que los latriká/Menonia corresponderían a la investigación exhaustiva acerca de la historia de las diversas disciplinas que Aristóteles habría encomendado a algunos de sus discípulos, y a Menón, en concreto, la de la literatura de contenido médico que se encontraba en la biblioteca del Liceo.

Ya incluso antes de que fuera editado, F. Kenyon lanzó la hipótesis según la cual un extenso papiro de contenido médico que había adquirido con los fondos del British Museum coincidía con la obra de Aristóteles reseñada por Galeno a la que se acaba de hacer referencia (Kenyon, 1892, pp. 237-240). En $1893 \mathrm{H}$. Diels asumió la hipótesis de Kenyon afirmando que la segunda sección del papiro Anónimo de Londres ${ }^{62}$ correspondía a un libre ejercicio, a un epítome, en base a las Menonia. Diels postuló también que el autor del Anonymus no tuvo acceso directo a las Menonia, sino que conoció dicha obra a través de una compilación del médico Alejandro Philalethes ${ }^{63}$ titulada Opiniones (Diels, 1893, pp. 414-415; Wellmann, 1922, p. 420). ${ }^{64}$ La "hipótesis Kenyon-Diels", es decir, la identificación de la segunda sección del papiro Anónimo de Londres con la obra de Aristóteles-Menón atestiguada por Galeno ha constituido la base general de la mayor parte de estudios sobre el papiro Anónimo de Londres. ${ }^{65} \mathrm{El}$ Anonymus Londinensis constituye la evidencia más notable de que en el Egipto de finales del s. I d.C. ${ }^{66}$ circulaba una doxografía médica - bajo el nombre de Aristóteles - de la que el escriba del Anonymus se sirvió para elaborar su escrito (Manetti, 1986, p. 62; Manetti, 1989, p. 351). ${ }^{67}$

La verdad, empero, es que las cosas se complican bastante cuando se examina más de cerca la cuestión. Para empezar no está nada claro quién fue el tal Menón. ${ }^{68} \mathrm{D}$. Manetti, la filóloga que lleva estudiando este papiro desde hace casi 30 años, cree que en los ss. I-II d.C. no se sabía de Menón mucho más de lo que hoy sabemos de él cosa que, a todo efecto, puede resumirse en un hecho: no se puede afirmar con rotun- 
didad que Menón hubiera existido (Manetti, 1986, p. 64; Manetti, 1990, p. 220). Además, según Manetti no es descartable que el papiro refleje una obra del propio Aristóteles a la que el escriba del Anonymus habría tenido todavía acceso directo. Según esto, la segunda sección del papiro sería un pasticcio de citas, reflexiones, y comentarios a propósito del De la salud y de la enfermedad del que se ha hablado más arriba, tratado que el escriba del papiro utilizó a razón de lo que estaba escribiendo (Manetti, 1986, pp. 59-64; Manetti, 1990, pp. 220-222; Manetti, 1994, pp. 47-58; Eijk van der, 2005, p. 264). Pero esto no es, aun si cabe, lo más alarmante de la cuestión.

La alternativa de Manetti a la "hipótesis KenyonDiels" queda en entredicho desde el mismo momento en que decide encabezar todas y cada una de las páginas de su edición del papiro ${ }^{69}$ con el título 'latriká'. Desde un punto de vista estrictamente papirológico esto representa un serio problema ya que no existe la más mínima traza de que el término 'latriká' pudiera haber sido escrito en el lugar donde la edición de Manetti indica su presencia (Ricciardetto, 2014, p. 41). Además, Manetti mete el término 'IATPIKA' entre paréntesis angulares (s.c. 〈IATPIKA), repitiendo después con la variante IATPICA ${ }^{70}$ dando así a entender que se trata, según las convenciones, de una palabra omitida por parte del escriba y, por otro lado, que ese era también el título ${ }^{71}$ de todo el papiro editado. Desconocemos el motivo de tamaño error, pero de acuerdo con el estado redaccional del papiro no hay argumentos que inviten a pensar que el escriba hubiera querido titular su escrito, ni tampoco que hubiera querido hacerlo de ese modo. ${ }^{72}$ Por tanto, si al título de Anónimo de Londres le añadiéramos la apostilla de Anónimo "intitulado" de Londres estaríamos haciendo, seguramente, bastante más justicia a la cuestión.

Aunque no se pueda afirmar que la segunda sección del Anonymus corresponda a una obra ni de Aristóteles ni de Menón (Ricciardetto, 2014, p. XXIX), por lo menos una cosa parece incontrovertible, y esta es que el contenido del papiro presenta - desde diversos puntos de vista - una fuerte impronta aristotélica (Gourevitch, 1989, p. 238; Manetti, 2014, p. 233) y no solo por las referencias explícitas que el papiro hace a Aristóteles. ${ }^{73}$ De las tres diferentes secciones temáticas en las que se dice que el Anonymus se encuentra dividido, es la segunda la que propiamente constituye una doxografía. Por 'doxografía' H. Diels entendió un género de escritos antiguos que recogen las opiniones (doxai, areskonta, placita) de los personajes que se tenían por legos en una disciplina particular. Se cree que una tal empresa empezó con el método dialéctico que se enseñaba en el Liceo, cuyos orígenes podrían encontrarse en los Tópicos. A principios del s. IV a.C. los autores médicos empezaron a interesarse por lo que habían hecho sus predecesores y a recopilar sus opiniones, organizando sus propias teorías en función de las de aquellos. En tercer lugar, la influencia de Aristóteles se puede apreciar en las cols. XXIII, 42-XXIV, 9 en las que el escriba del Anonymus hace alusión a un pasaje del De somno et vigilia (Manetti, 1986, p. 69). ${ }^{74}$ Parece que esta referencia está basada en el conocimiento directo de dicho tratado. Otro influjo aristotélico lo encontramos en los criterios taxonómicos ${ }^{75}$ y en el léxico empleado a lo largo de todo el papiro. Aristóteles fue el primero en desarrollar un análisis científico de las partes constituyentes del cuerpo (Marenghi, 1961, p. 142) ${ }^{76}$; distinciones de las que el escriba del papiro se sirve a la hora de hablar de las partes 'continuas ${ }^{177}$ o de las partes 'homoiomerē'. ${ }^{78}$ Ligado a este cuarto aspecto, otro ámbito en el que también se hace notar la influencia de Aristóteles en el papiro es en el uso de determinados conceptos, entre los que destacan dos en especial: entrécheia ${ }^{79}$ y períttōma.

Después de todo lo dicho hasta aquí, tras este periplo a través de catálogos, tratados, manuscritos y papiros nos encontramos ante un incómodo vacío que ciertamente dificulta la tarea de proporcionar una idea más o menos cabal acerca de cuáles pudieron haber sido las doctrinas médicas de Aristóteles. Pese a todas las razones esgrimidas al inicio por las que se ha apuntado a un vínculo estrecho entre Aristóteles y la medicina, el caso es que no conservamos ninguno de los diagramas de las Disecciones, ni se conserva el tratado Sobre la enfermedad y la salud, ni parece nada probable que Aristóteles hubiera escrito el libro $\mathrm{X}$ de la Historia animalium, como tampoco podemos decir que los Problemas fueron obra de Aristóteles. Incluso en el supuesto de que Aristóteles - y no Menón - hubiera escrito los latriká deberíamos admitir que dicha obra nos ha llegado de una forma tan diluida y deformada a través del papiro Anónimo de Londres que apenas puede sernos de utilidad a la hora de representarnos, de un modo fidedigno, qué es lo que Aristóteles sostuvo sobre el asunto. Debemos buscar a Aristóteles solo en la segunda sección del papiro, y aún con todo, no obtenemos un vivo retrato de sus doctrinas acerca de la medicina, sino que lo que encontramos es un Aristóteles tamizado a través de la opinión del escriba y quizá también, como Diels pensó, este todavía lo conociera a partir del escrito doxográfico de Alejandro Philalethes; por lo que entre "el Aristóteles" del Londinensis y nosotros operan por lo 
menos 2 (ó 3) interfaces, y con esto el nivel de verosimilitud y de objetividad exigible dista mucho de ser el deseado. ${ }^{80}$ Además, así como el escriba del papiro cita a Platón como autoridad en el ámbito de la medicina (Eijk van der y Francis, 2009, p. 217) ${ }^{81}$, no puede decirse lo mismo con respecto a Aristóteles; por lo menos tal y como el papiro ha llegado hasta nosotros. El escriba no individua a Aristóteles como un médico cuyas doctrinas sobre el origen de las enfermedades son conocidas, o se pueden encontrar en tal o cual tratado; más bien parece que el autógrafo del Londinensis utiliza a Aristóteles como fuente de donde extrae las informaciones concernientes a los otros 20 médicos sobre los que trata a lo largo de la segunda sección.

Dicho esto, ante un tal estado de cosas el único malabarismo intelectual que podemos permitirnos es el de intentar esbozar, a partir de los textos que en general se tienen por aristotélicos, qué es lo que el escriba del Anonymus podría haber dicho acerca de Aristóteles en el caso de que lo hubiera incluido en la segunda sección del papiro.

\section{ARISTÓTELES Y LA MEDICINA; UNA RECREACIÓN}

En contra de lo que podría parecer a primera vista, no está tan claro que el escriba hubiera adscrito a Aristóteles al primero de los grupos representados en la segunda sección, es decir, al de los médicos que creían que las enfermedades se debían a los residuos (perittốmata) $^{82}$ de los alimentos no digeridos. Cabe pensar que Aristóteles hubiera ocupado un lugar de transición entre este y el otro de los grupos de la segunda sección, el de los médicos que postularon que las enfermedades se debían a los elementos constitutivos del cuerpo (stoicheĩa). ${ }^{83}$ Pues si, por un lado, bien es cierto que el concepto de períttōma fue acuñado por Aristóteles (Nelson, 1909, p. 105; Thivel, 1965, p. 268; Eijk van der, 2014, p. 364) ${ }^{84}$ y que las nociones de medida y de proporción juegan un papel importante en su pensamiento, la definición de períttōma que da Aristóteles en el De generatione animalium ${ }^{85}$ no parece implicar ningún aspecto mórbido (Manetti, 2005, p. 312); más bien lo contrario, el períttōma viene ahí descrito como un agente inocuo relacionado con la formación del esperma. ${ }^{86}$ De acuerdo con Aristóteles, en el caso de que atribuyéramos a los residuos alimentarios el hecho de ser el principal agente patógeno, pero por otro lado, y también, la materia que posibilita la vida estaríamos incurriendo en una flagrante contradicción, ya que desde la óptica de Aristóteles es inconcebible que para una misma causa se puedan dar dos resultados así opuestos; pues, si las causas son las mismas los resultados deben ser los mismos. ${ }^{87}$ Tendríamos ciertamente dificultades en explicar cómo la misma entidad de la que se dice que causa la enfermedad es, a la vez, decisiva para la generación. ${ }^{88}$ Aristóteles distinguió la noción de 'períttōma' de la de 'sýntēgma's9, siendo esta última siempre de naturaleza mórbida (nosốdēs). Por 'sýntēgma' se entiende algo supuestamente diferente de 'períttōma', a saber, los "humores" que permean el cuerpo y que se segregan o excretan regularmente. De ahí que haya que decir que en Aristóteles, a diferencia de lo que parece ocurrir en el Anonymus, el uso del término 'períttōma' sugiere algo inútil o superfluo pero ni particular ni necesariamente nocivo o patógeno. ${ }^{90}$ De modo que nos encontramos ante dos opciones distintas: o bien Aristóteles hizo distinción entre 'perittốmata' y 'sýntēgmata' (atribuyendo a los segundos una naturaleza mórbida); o bien Aristóteles postuló la existencia de dos tipos de residuos, unos útiles y otros inútiles, siendo los residuos inútiles (syntégmata) los que propiamente causan la enfermedad.

Por otro lado, la doctrina de Aristóteles como un modelo de transición entre los dos grupos caracterizados por el escriba vendría avalada por el hecho de que Aristóteles concibió el cuerpo humano como un compuesto, como el resultado de una agregación sucesiva de elementos. De acuerdo con Aristóteles, los principios cósmicos actúan en primer lugar a través de los cuerpos elementales y sus movimientos simples. Mediante un proceso de mezcla, estos cuerpos dan lugar a las partes más simples de los organismos. A su vez, también agregándose, dichas partes originan partes más complejas, tejidos y órganos, siendo el sistema de estos últimos lo que constituye el organismo. ${ }^{91}$ Para Aristóteles las cuatro causas o cualidades de los elementos son lo caliente, lo frío, lo seco y lo húmedo atribuyendo a la primera, al calor, la mayor parte de procesos biológicos. ${ }^{92}$ Para Aristóteles el calor es un elemento activo que - como el frío - determina, forma y transforma los cuerpos. De ahí que sea difícil predecir de qué lado o a qué grupo el escriba hubiera puesto a Aristóteles.

Si se tienen en cuenta algunos pasajes del Corpus Aristotelicum se observará que Aristóteles dio especial relevancia a la digestión (pếpsis) ${ }^{93}$, seguramente debido, como se verá, a su relación con el origen de diversos tipos de enfermedades. Aristóteles pensaba que la digestión también se producía por la acción del calor ${ }^{94}$, equiparándola a uno de los tres tipos de cocción ${ }^{95}$, la ebullición. La digestión se daba por la acción del calor del cuerpo sobre una sustancia líquida o un 
ambiente húmedo. ${ }^{96}$ Aristóteles atribuyó al calor connatural del cuerpo la tarea de asimilar los nutrientes. En su opinión, los fluidos resultantes de la ebullición que se daba en el estómago eran luego distribuidos por una red de finos vasos en los intestinos. A continuación, dichos fluidos pasaban a través de los poros gracias a un proceso similar a la evaporación, convirtiéndose en una especie de suero (íchōr) que, en su ascensión paulatina por el cuerpo, se transformaría finalmente en sangre ${ }^{97}$ después de haber experimentado una serie de cocciones: la primera en los intestinos, después en el hígado, más tarde en el bazo y los riñones y, finalmente, en el corazón (Allbutt, 1921, p. 247; Tacchini, 1996, pp. 88-90).

No es extraño, pues, que algunos tipos de dispepsia se expliquen por causa de una semicocción del alimento ingerido. ${ }^{98}$ Aristóteles afirmó que el aire encerrado en el cuerpo que resultaba de los gases que se desprendían de los residuos que se formaban a partir de las ingestas demasiado copiosas, que contenían ingredientes muy dispares o muy difíciles de digerir eran causa de temblores, palpitaciones, convulsiones y espasmos incontrolables. ${ }^{99}$ Aristóteles creía que los flatos que se producían durante la digestión cuando se enfriaban en la cabeza provocaban catarros ${ }^{100}$, pesadi$\|_{\text {las }}{ }^{101}$, la deformación de ciertas partes del rostro ${ }^{102}$, o incluso el emblanquecimiento del pelo. ${ }^{103}$ Aunque en estado germinal, en los escritos de Aristóteles podemos encontrar las bases de toda la pneumatología médica posterior. En este sentido la doctrina etiológica de Aristóteles no se encontraría lejos de la de $\mathrm{Hi}$ pócrates ${ }^{104}$, o mejor dicho, de las doctrinas de Hipócrates tal y como parece que estas fueron conocidas y asimiladas por Aristóteles.

En efecto, las columnas V, 35-VI, 43 del papiro Anónimo de Londres ponen en evidencia que en el Liceo se conocían los escritos de Hipócrates, a la vez que reflejan que en el Liceo se profesaba una interpretación "heterodoxa" - equivocada en opinión del escriba del hipocratismo. ${ }^{105}$ Lo que el autor del papiro dice es que de acuerdo con Aristóteles (y/o Menón) Hipócrates debería considerarse como un representante de los médicos que creen que los residuos constituyen el origen de las enfermedades pero que, de hecho, esto no es así, y como contrargumento el escriba aduce al De natura hominis ya que, en su opinión, es ahí donde hay que acudir para leer la verdadera doctrina de Hipócrates ${ }^{106}$ en lo tocante a las causas de la enfermedad. Sin duda el argumento esgrimido por el escriba se ajusta mucho más a la teoría humoral que la tradición nos ha legado respecto a Hipócrates, pues, según los contenidos del De natura hominis Hipócrates formaría parte del segundo de los dos grupos de médicos reseñados en la segunda sección del Anonymus. Esto si no fuera porque la objeción del escriba presenta dos dificultades. La primera es que la lectura del papiro en este punto es incierta ${ }^{107}$, por lo que solo se puede intuir que el escriba está haciendo referencia al De natura hominis. La segunda y mayor de las trabas es que Hipócrates no fue el autor de dicho tratado sino su yerno Pólibo de $\operatorname{Cos}^{108}$, también médico; vínculo en virtud del cual la teoría de uno acabó adscrita al otro. A partir de los contenidos que el escriba expone inmediatamente a continuación ${ }^{109}$ podemos suponer, sin embargo, que el papiro sí hace alusión al De natura hominis pues, aunque crea que se trata de una explicacion que no se ajusta a los hechos, el escriba afirma que aparte de por un enfriamiento o un calentamiento excesivo de la bilis y de la flema Hipócrates estableció otras dos posibles causas de la enfermedad: el aire y los hábitos alimentarios o el tipo de dieta, siendo la primera de ellas la que actúa cuando un gran número de personas contraen a la vez una y la misma enfermedad. En el Corpus hippocraticum son pocas las ocasiones en que el término 'epidemia' toma el sentido que normalmente le atribuimos ${ }^{110}$, siendo precisamente este el caso que encontramos en el De natura hominis. ${ }^{111}$

\section{CONCLUSIONES}

Es difícil creer que Aristóteles hubiera practicado la medicina de acuerdo con la acepción más básica de lo que es un 'médico' (aquella que él mismo da en primer lugar en la Política); por lo que Aristóteles en algún modo fue "la oveja negra" de la familia. No obstante, que no la practicara no significa que no se hubiera interesado por ella. Después de todo lo expuesto hasta aquí puede decirse que sí lo hizo, aunque desde un plano absolutamente teórico. ${ }^{112}$ Es precisamente en esta clave que podemos pensar que la representación del cuerpo humano y de los procesos fisiológicos en el mismo que encontramos en el Corpus Aristotelicum se obtuvieron a partir de lo que Aristóteles pudo constatar que ocurría en el mundo natural, o asimismo, por analogía (o extrapolación) a lo que observó en los diferentes animales que diseccionó. Eso explica también el modo particular, doxográfico, con el que Aristóteles se acercó a las doctrinas médicas, especialmente a la de Hipócrates. Así como Hipócrates se centró en la enfermedad y en las técnicas para combatirla, Aristóteles lo hizo sobre la salud, subordinando la técnica a los principios teóricos. El conocimiento de las causas de la enfermedad era para Aristóteles muy 
superior al saber práctico y útil del médico corriente (Viano, 1984, pp. 327-328; Eijk van der, 2014, pp. 367-368). Qué remedios cabía aplicar en el caso de tal enfermedad o de tal afección era algo secundario para Aristóteles, los fundamentos de la terapéutica no se basaban en la efectividad sino en su administración de acuerdo con unos principios universales de la naturaleza que, en definitiva, daban razón de la eficacia de un emplasto o de otra sustancia cualquiera.

En consecuencia, y dentro de las reservas pertinentes, Aristóteles se ocupó de un ámbito particular de la medicina que se conoce como 'Higiene', o en otras palabras, de la investigación acerca de salud del cuerpo y de los medios de su conservación (Jaeger, 1945, pp. 30-31; Debru, 1996, p. 244). Para Aristóteles la salud era un fin natural ligado a la misma estructura material de los cuerpos. La salud de un organismo se manifestaba en la mezcla proporcional entre el frío y

\section{NOTAS}

1. Para un panorama general de la cuestión (Bidez, 1943, pp. 11-25; Moraux, 1951, p. 1; Lee Too, 2010, pp. 24-29).

2. En el conjunto del Corpus Aristotelicum Hipócrates es mencionado solo una vez en Pol. VII 5, 1326a 15, y sin ningún propósito médico. La excepción a la regla es el escaso puñado de médicos que Aristóteles cita casi siempre, hay que decir, para criticar sus doctrinas. En HA III 2, 511b 10-513a 10 encontramos los nombres de Siénesis de Chipre - también citado en Hipócrates Oss. VIII (IX p. 175 Li.), Diógenes de Apolonia y Pólibo; en GA IV 1, 765a 25 Aristóteles menciona a un tal Leófanes, y en EE VII 10, 1243b 23 hace una fugaz referencia a Heródico. (Eijk van der, 2014, pp. 348-350). Para las citas de los tratados de Hipócrates y de Galeno (véase el apartado 'EDICIONES DE OBRAS DE AUTORES ANTIGUOS' en la bibliografía) se han utilizado las abreviaciones tal y como aparecen en: Fichtner, Gerhard (2015), Corpus Hippocraticum. Bibliographie der hippokratischen und pseudohippokratischen Werke, Berlín, Berlin-Brandenburgischen Akademie der Wissenschaften; Fichtner, Gerhard (2015), Corpus Galenicum. Bibliographie der galenischen und pseudogalenischen Werke, Berlín, Berlin-Brandenburgischen Akademie der Wissenschaften. Para las citas de los diálogos de Platón y de los tratados de Aristóteles (véase el apartado 'EDICIONES DE OBRAS DE AUTORES ANTIGUOS' en la bibliografía) se han empleado respectivamente las abreviaciones de las páginas XXXIII y XIX del epígrafe I 'Authors and Works' del diccionario Liddell, Henry George; Scott, Robert (1996), A Greek-English Lexicon (with a Revised Supplement), Oxford, Clarendon Press.

3. Algunos de ellos aducen, además, que la medicina no tuvo cabida en el Liceo por el hecho de tratarse de un arte productivo, i. e. no liberal. (French, 2000, p. 76). Hay que recordar que los antiguos consideraron la medicina como una téchne, la iatriké techne, con una clara aplicación práctica: restablecer la salud. (Horstmanshoff, 1990, pp. 176, 197; Grmek, 1997, p. 56; Eijk van der, 2005, p. 263). el calor, tanto en el seno de un organismo como en la relación de este con su ambiente ${ }^{113}$; o como un equilibrio entre lo que un cuerpo ingería y lo que un cuerpo consumía ${ }^{114}$. Esta proporción ideal era lo que en último término permitía colegir qué era excesivo y qué era deficitario en relación a un cuerpo particular, y poder paliar así las posibles situaciones extremas ${ }^{115}$ mediante un remedio apropiado. Si la salud se concibe como una proporción la enfermedad vendrá definida como una desmesura, como un desequilibrio que debe restablecerse suprimiendo lo que se encuentra en exceso o restituyendo aquello que falta; en resumen, aplicando aquellas medidas que tienen el efecto opuesto a una condición dada (contraria contrariis curantur) ${ }^{116}$. De ahí que el principio higiénico general sea el de evitar cualquier tipo de exceso (hyperbolế), y que el patrón terapéutico que encontramos en los escritos de Aristóteles sea fundamentalmente alopático. ${ }^{117}$

4. Se considera que Alcmeón fue el iniciador del diagnóstico médico en Occidente (Laín Entralgo, 1981, p. 10) y, aunque somera, también el primero en hacer la importante distinción entre venas llenas de aire y venas llenas de sangre. Se cree que practicó disecciones y vivisecciones. (Bidez y Leboucq, 1944, pp. 13, 16, 39).

5. Galeno De meth. med. I 1 (X p. 6, 3 K.). (Viano, 1984, p. 312; Graham, 2010, pp. 336-337).

6. (Horne, 1963, p. 319).

7. Según Galeno De plac. Hipp. et Plat. II 8 (V pp. 281, 12-284, $3 \mathrm{~K}$.) es Diógenes quien sentó las bases teóricas de la fisiología que más tarde utilizaría Aristóteles.

8. (Viano, 1984, p. 319).

9. En el sentido de aquella parte de la filosofía que se ocupa del estudio de la naturaleza. (Giannantoni, 1984, p. 64). Es importante remarcar que Aristóteles concibió la medicina como una rama de la filosofía física. Aristóteles Long. I 464b 35-465a 1; Resp. XXI 480b 22-30. (Viano, 1984, p. 325; Manetti, 1986, p. 62; Longrigg, 1993, p. 152). De ahí que una de las formas para decir 'médico' en inglés sea 'physician'. (French, 2000, pp. 78-81).

10. Aristóteles Sens. I 436a 19-b 1; Resp. XXI 480b 24-30. (Longrigg, 1993, p. 151; French, 2000, p. 78; Eijk van der y Francis, 2009, pp. 215, 226; van der Eijk, 2014, p. 357 n. 36).

11. En lo referente por ejemplo a las teorías de Empédocles Cf. Aristóteles Metaph. I 3, 984a 8-11; 4, 985a 21-b 4; III 4, 1000b 7-20; GC | 8, 324b 26-35; || 6, 333a 18-7, 334a 21; Ph. IX 5, 250b 26-29; Resp. VII 473a 15-474a 7; GA IV 1, 764a 1-6; PA I 1, 640a 19-25; Cael. II 13, 295a 17-20; III 2, 300b 29-31; 6, 305a 3-4... 
12. Hipócrates no solo afirmaba ser descendiente de Asclepio, hijo de Apolo (según la variante genealógica que se tome, la suya era la decimoséptima, decimoctava o decimonona generación después de Asclepio), sino también descender de Hércules, héroe sin duda relacionado con la sanación.

13. Es cierto, no obstante, que a partir del s. V a.C. la medicina experimenta un proceso de disvinculación del ámbito familiar que la caracterizaba en las primeras fases de su desarrollo en Grecia. (Marganne, 2004, pp. 19-20). Pese a haber sido publicados por los primeros discípulos de $\mathrm{Hi}$ pócrates, la difusión de los textos médicos fuera del ambiente estrictamente médico está atestiguada y fue mayor de lo que podría parecer. (Nelson, 1909, 91-97; Manetti, 2014 , p. 234). Un hecho a tener también en cuenta en este sentido es que es muy improbable que algunos tratados del Corpus Hippocraticum como Flat. o Vet.med. hubieran sido escritos por médicos o por alguien que practicase la medicina. (Eijk van der, 2005, p. 269).

14. (Zeller, 1879, p. 4; Longrigg, 1993, p. 149; Gigon, 1987, p. 511). El padre de Aristóteles ejerció como archiatros avant la lettre, pues era así como se conocía a los médicos que ejercían en la corte imperial o en las casas reales durante el período helenístico. (Nutton, 2004, p. 152).

15. Por así decirlo, el tándem emperador/médico será una figura recurrente a lo largo de todo el periodo imperial: Nerón y Tésalo de Tralles, Marco Aurelio y Galeno, Juliano el Apóstata y Oribasio, etc. (Marcone, 2006, pp. 268-269).

16. En el testamento de Aristóteles se dice que Aristóteles confía su hija a Nicanor.

17. Al margen de fragmentos puntuales como Aristóteles Sens. I 1, 436a 17-b 1 ó Resp. XXI 480b 22-24, seguramente el de Mete. IV 2, 379b 10-4, 382a 21 puede considerarse como el más relevante en lo que a este tema concierne.

18. Una tal formación pudo tener su origen en una de las partes constitutivas de la medicina teórica, la llamada instrucción oral (akróasis). (Drabkin, 1944, pp. 335-336, 342-344).

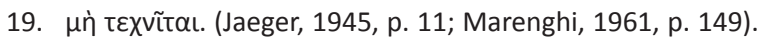
De hecho el estudio de las artes (téchnai) honraba a quienes se aplicaban a ellas si, y solo si, lo hacían desinteresadamente, sin ninguna pretensión de comerciar o de enriquecerse con ello. (Moraux, 1951, p. 110; Horstmanshoff, 1990, p. 193; Debru, 1995, p. 75).

20. El sustantivo iatrós está sin duda vinculado con el verbo curar (iáomai). (Perilli, 2006, p. 38).

21. Aristóteles Pol. III 6, 1281b 38-1282a 8; PA I 1, 639a 4-8.

22. Quizás la acepción moderna (académica) de 'doctor' pudiera remontarse a este segundo significado.

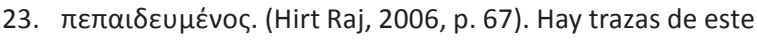
mismo término en Platón Prt. 347d; Lg. 654 b-c, 658d, y sobre todo en Chrm. 156 b-c donde Platón presenta la figura del pepaideuménos diciendo que los buenos médicos practican su disciplina desde una perspectiva mucho más amplia y teórica. (Jori, 1995, pp. 414-416; Eijk van der, 1995, p. 451). Plinio el Viejo constituye un claro ejemplo de lo que se entiende por un pepaideuménos, es decir, de alguien que pese no haber practicado jamás la medicina se deleitaba sin embargo instruyéndose con literatura médica. En este sentido, por tanto, Plinio podría llamarse perfectamente 'médico' según la tercera acepción dada por Aristóteles. A raíz de esto puede entenderse también por qué el único manual sistemático de medicina que se ha conservado de la Antigüedad, el De medicina de Celso (ca. 30 d.C.), nos ha sido transmitido precisamente por un erudito que no era médico de profesión. (Andorlini y Marcone, 2008, p. 49).

24. En los primeros siglos de la era cristiana se sobreentendía que un médico era alguien que había sido perfecta y altamente educado, razón por la que a menudo se representa a los médicos de la época manejando libros. (Drabkin, 1944, p. 334; Marganne, 2009, p. 260). Esto no obstante contrasta con las opiniones de otros expertos según los cuales el nivel de alfabetización completa (leer y escribir) entre los profesionales de la medicina de principios de la era cristiana era bastante más bajo de lo que cabría esperar.

25. En Sens. I 436a Aristóteles remarca que el filósofo de la naturaleza debe conocer los principios de la salud y de la enfermedad, pero no las técnicas de su tratamiento. (French, 2000 , pp. 78,81 ). A esto podría objetarse sin embargo que Caelio Aureliano en su tratado Celerum passionum II 13 (87) cita ad pedem litterae una obra de Aristóteles que lleva por título De los remedios (De adiutoriis). (Eijk van der y Francis, 2009, p. 220 n. 3)

26. Por citar solo algunas Aristóteles Ph. II 1, 193b 12-15; V 5, 229a 11-16; Rh. I 6, 1362a 31-34; Pol. III 11, 1281b 391282a 6; 15, 1286a 12-14; EN I 6, 1097b 28-33; 13, 1102a 18-23; 1102b 18-21; III 6, 1113a 26-29; X 10, 1181b 3-5. (Lloyd, 1968, pp. 72-78).

27. G. E. R. Lloyd, por ejemplo, quien ha estudiado con detenimiento este asunto, cree que Aristóteles las usó como meros instrumentos retóricos y, por ende, que todas las analogías médicas que encontramos sobre todo en la Ética Nicomáquea no aportan ninguna luz al presente estudio. (Lloyd, 1968, pp. 68, 82).

28. Galeno De anat. admin. II 1 (II p. 282, 2-3 K.). (Giannantoni, 1984, p. 66; Viano, 1984, p. 313; Longrigg, 1993, pp. 161-162).

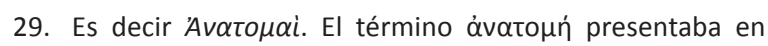
griego un sentido bastante más amplio que el actual. Así, por ejemplo, podía designar 'apertura para ver las partes internas y más profundas', comprendiendo tanto la Fisiología experimental como la Anatomía. A veces significa 'demostración' o 'descripción de las partes'. En Rufo de Éfeso particularmente designa el 'arte de la disección'. (Daremberg y Ruelle, 1879, p. 630). En Aristóteles el sig- 
nificado es también amplio puesto que abarca cosas tan dispares como 'visión efectiva propia', 'visión efectiva por parte de otros', 'dibujos y reconstrucciones de estructuras internas nunca observadas', 'inferencia de casos concretos dados por observados a casos nunca observados o inobservables' etc. (Viano, 1984, p. 338).

30. Diocles creía que los fetos de los mamíferos se alimentaban succionando una especie de pezones que sobresalían de las paredes del útero, cosa que contrasta claramente con la opinión de Aristóteles quien, por observación directa (dià tỗn anatomỗn), refutó una tal hipótesis afirmando que la placenta impedía cualquier tipo de alimentación por succión. Aristóteles GA II 7, 745b 34-746a 28.

31. Aristóteles HA I 17, 497a 32; III 1, 510a 30-35; 511a 13; IV 1 , 525a 8-9; VI 10, 565a 12-13; 11, 566a 14-15; PA IV 5, 680a 1-3; 10, 689a 16-20. (Marenghi, 1961, p. 144; Longrigg, 1993, pp. 150, 161-162; Longrigg, 1995, p. 438).

32. Aristóteles Resp. IV 472a 4-5; Juv. XVI, 478a 34-b 1. (Grmek, 1997, pp. 64-65).

33. Especialmente Diocles de Caristo, (Nutton, 2004, pp. 119120, 128).

34. Aristóteles $P A$ I 5, 645a 5-23 por ejemplo parece aludir a la necesidad del análisis anatómico a fin de obtener conocimiento acerca de ciertas partes del cuerpo de un animal. (Repici, 2006, p. 76). Otros pasajes en los que Aristóteles se refiere a conclusiones a las que llega, verosímilmente, a partir de sus propias observaciones son GA IV 1, 764a 3435; PA IV 2, 677a 9-10.

35. Se sabe, además, que las campañas militares de Alejandro Magno contaban con equipos de profesionales que cartografiaban los lugares a los que llegaban o describían lo que iban encontrando a su paso, así como también se encargaban de enviar a Atenas los nuevos especímenes de plantas y animales descubiertos.

36. Aristóteles HA III 3, 513a 12-15.

37. Por ejemplo en PA III 4, 666b 20-22 ó en HA III 3, 513a 30 Aristóteles yerra al decir que el corazón de los animales de gran tamaño está constituido por tres cámaras y el de los de pequeñas dimensiones por dos. Asimismo en HA II 3, 501b 19-21 Aristóteles incurre en craso error al afirmar que las mujeres tienen menos dientes que los hombres.

38. Herófilo y Erasístrato (ss. IV-III a.C.) son conocidos por su trabajos pioneros en lo que a la investigación anatómica se refiere gracias al mecenazgo del faraón Ptolomeo II Filadelfo. (Ricciardetto, 2014, pp. XLVI-XLVII).

39. Aristóteles PA IV 10, 689a 17-21; HA I 16, 494b 21-24; III 2, 511b 13-19. (Bidez y Leboucq, 1944, p. 13; Byl, 2011b, p. 118).

40. Aristóteles Sens. I 1, 436a 17-18; Resp. XXI 480b 21-24; Long. 1, 464b 32-33; PA II 7, 653a 8-10. (Gigon, 1987, p. 511; Nutton, 2004, p. 58; Eijk van der y Francis, 2009, p. 220 n. 30; Ricciardetto, 2014, p. XXIX n. 125).

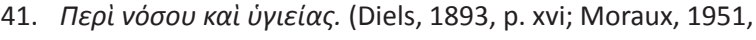
pp. 110, 186-193; Manetti, 1986, p. 61). Los autores posteriores conocieron dicho tratado con alguna ligera variación

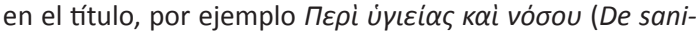

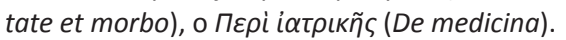

42. Aristóteles Resp. XXI 480b 22-30.

43. Alejandro de Afrodisia In librum de sensu commentarium

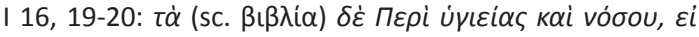

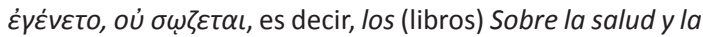
enfermedad, si es que existieron, no se conservan. (Heitz, 1865, p. 58; Lloyd, 2003, p. 176; Eijk van der, 2005, p. 263).

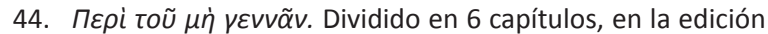
de 1 . Bekker el libro $X$ de la Historia animalium comprende 633b 10-638b 38.

45. Un examen detallado de los exvotos hallados en Epidauro revela que la esterilidad constituyó el motivo de consulta de más de la mitad de las mujeres que se acercaron al templo. Por lo general la esterilidad era algo que se achacaba a la mujer. En este sentido, el capítulo XXII del tratado hipocrático Aires, aguas y lugares, en el que se aborda la infertilidad masculina, constituye la excepción a la norma. (Byl, 2011a, pp. 121, 126). Es importante mencionar que en los ss. V-IV a.C., es decir, antes de que Herófilo los descubriera, no se sabía de la existencia de los ovarios ni tampoco de las trompas de Falopio, sino que se creía que el útero constituía el único órgano genital femenino. (Byl, 2011a, pp. 127-128; Byl, 2011b, p. 123).

46. En el s. IV d.C. el libro X había sido incorporado a los 9 previos de la Historia animalium porque al citar un pasaje del libro $X$ Oribasio ya lo considera como parte integrante de la Historia animalium. Cf. Oribasio Collectionum medicarum (Libri incerti) XIII 1 (65)-14 (68) que hace referencia a Aristóteles $H A$ X 5, 636b 39-637a 10. (Berger, 2005, pp. 30-31).

47. Los pertenecientes a la familia $\alpha$ del stemma codicum de las HA: Laur. 87,4 (s. XII); Marc. 208 (coll. 614) (s. XIII); Vat. Palat. 260 (ca. 1300). El W Par. suppl. 1156, el más antiguo (s. IX), no es útil aquí porque solo recoje dos breves pasajes: Aristóteles HA VI 11, 567a 10-13; 14, 569a 1.

48. No sabemos si eso se debió a la decisión expresa de algún representante del perípato, de algún catalogador de las obras de Aristóteles o bien a un error o a un despiste en la parádosis de las mismas. Podemos pensar que una tal integración tuvo lugar en algún momento entre los ss. III-IV d.C.

49. Cf. e.gr. Aristóteles $H A X 1,633 b$ 15; 634a 12-13; 2, 634b 32; 4, 636b 2-6. (Eijk van der, 2005, p. 267).

50. El autor del libro $X$ describe una afección a la que llama 'falso embarazo/embarazo flato' así como sus causas, sintomatología, diagnóstico y terapia (aunque no indique exactamente de qué se trate). Aristóteles $H A \times 3$, 636a 9-26. 
51. La clave aquí está en el uso del verbo Gıyүávw y derivados, cuyo significado es inequívocamente el de 'tocar, palpar, aprehender o alcanzar mediante el tacto'. Cf. Aristóteles $H A \times 2$, 635a 6-14; 3, 635b 15-16; 7, 638b 16-38.

52. Aristóteles $H A \times 7,638 \mathrm{~b}$ 16-38. Lo que el autor les reprocha es que cuando no hay embarazo estos quistes aparecen fríos al tacto. Cf. Aristóteles GA IV 7, 775b 25-33; Hipócrates Mul. I 71 (VIII pp. 148, 24-150, 22 Li.).

53. La excepción a esta opinión general la encontramos en van der Eijk, quien piensa que Aristóteles sí es el autor del libro $X$ de la HA. (Eijk van der, 2005, pp. 262, 265).

54. El manuscrito más antiguo de los Problemas se remonta al s. X d.C.

55. Pseudo Aristóteles Pr. | 41-43, 864a 2-b 11. Dicha definición debe leerse en paralelo a la explicación que encontramos en Hipócrates Loc. Hom. VL (VI p. 340, 3-12 Li.). (Marenghi, 1965, p. 65 n. 59).

56. G. Marenghi o S. Byl defienden que Aristóteles y sus discípulos tuvieron acceso a un repertorio todavía mucho más amplio de escritos atribuidos a Hipócrates. (Longrigg, 1995, p. 432; van der Eijk, 2014, pp. 351 n. 18, 366; Manetti, 2014, pp. 234, 240).

57. Eliano Varia Historia IX 22 (ss. II-III d.C.); Diógenes Laercio Vitae philosophorum V 110 (s. III d.C.) y una versión de este último del año 1462 que se encuentra en el Fr. Matritensis gr. 4676.

58. Galeno In Hipp. Nat. Hom. comment. I 1 (XV pp. 25, 15-26, 2 K.). (Gigon, 1987, p. 512 fr. 354).

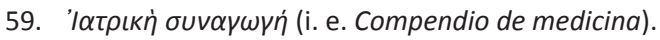

60. (Diels, 1893, pp. 77-78). De hecho esta hipótesis se da por sentada en la Realenzyklopädie. (Raeder, 1931, p. 927; Manetti, 1989, p. 348). Hay una corriente de especialistas, entre la que figura P. Moraux, que identifica los Problemas con los Menonia. (Marenghi, 1961, p. 146).

61. Cf. supr. § 3.2.

62. Es decir la sección del P. Brit. Lond. inv. $137=$ Pack $^{3} 2339$ comprendida entre las cols. IV, 18-XXI, 8. Siguiendo la primera edición de Diels, la segunda sección se encuentra reproducida en (Gigon, 1987, pp. 512-521 fr. 355). La edición más completa del papiro es a nuestro entender la de Ricciardetto, Antonio (2016), L'Anonyme de Londres. P.Lit. Lond. 165, Brit. Lib. inv. 137. Un papyrus médical grec du ler siècle après J.-C., París, Les Belles Lettres.

63. A pesar de que fue discípulo de Asclepíades de Bitinia lo cierto es que Alejandro Philalethes alcanzó la más alta posición en la escuela de Herófilo, caso sin duda insólito. Para una descripción exhaustiva de Alejandro Philalethes (50 a.C.-25 d.C.) consúltese el capítulo que se le dedica en (Staden von, 1989, pp. 532-540).

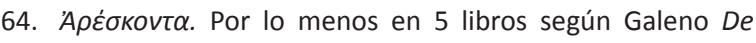
diff. puls. IV 4-5 (VIII pp. 725, 17-732, 7 K.). (Staden von, 1989, pp. 533 n. 9, 538). Alejandro Philalethes es citado en tres ocasiones en el Anonymus: cols. XXIV, 32-33; XXXV, 22; XXXIX, 1. La discusión acerca de las opiniones de Erasístrato que encontramos en la tercera sección del papiro (e.gr. cols. XXIII, 12-17; XXVI, 31-48) no puede atribuirse ni a Aristóteles ni a Menón porque Erasístrato vivió cuando ambos ya habían muerto. Este detalle confirmaría la hipótesis de H. Diels, es decir, que el escriba del Anonymus conoció los latriká por medio de las Opiniones (Aréskonta) de Alejandro Philalethes.

65. (Thivel, 1965, p. 266; Manetti, 1986, p. 60; Manetti, 1989, p. 348; Eijk van der, 1995, p. 452 n. 20; Ricciardetto, 2014, pp. XXVIII, LXI). De hecho no implica ninguna incompatibilidad que lo que actualmente leemos en la segunda sección del papiro fuera tanto obra de Aristóteles como de Menón, pues puede que Menón hubiera cumplido el encargo que se le encomendó y que Aristóteles utilizara dicho trabajo para su tratado Sobre la enfermedad y la salud.

66. En lo concerniente a la datación del Anonymus, tanto en base a las evidencias de tipo paleográfico como comparativo parece altamente seguro que fue escrito en el último cuarto del s. I d.C.

67. A esto hay que decir, no obstante, que en contraste con la exactitud con la que el escriba cita los nombres de todos los médicos a los que menciona este omite, en cambio, el título de cualquier tratado que pudiera haber utilizado para escribir los contenidos en el papiro. Es difícil afirmar si esta era la tónica en el s. I d.C. o si, de lo contrario, se trata de una cierta propensión particular del autor. Tampoco está claro si el escriba conoció directamente el latrikà atribuido a Menécrates (col. XIX, 19) o si cita dicha obra a partir de la doxografía homónima, las latrikà de Menón, de la que según Kenyon y Diels se sirvió. La cuestión permanece irresuelta cuando se aplica a la larga paráfrasis a la sección médica del Timeo de Platón que se hace en el papiro, pues el escriba no menciona en ningún momento el título del diálogo. (Manetti, 1999b, pp. 528-579).

68. Como dato relevante decir que Menón solo se conoce a través de la susodicha mención por parte de Galeno. Cf. supr. n. 58. (Withington, 1929, p. 183; Manetti, 1986, p. 61; Manetti, 1989, p. 348).

69. Manetti, Daniela (2011), Anonymus Londiniensis: De Medicina, Berlín, Biblioteca Teubneriana.

70. (Manetti, 2011, p. 1 et passim).

71. Si el Anónimo es un escrito 'hipomnemático', tal y como parece a juzgar por su estado actual, no es necesario que el escriba le hubiera puesto ningún título ya que los escritos de este tipo estaban, por lo general, desprovistos de título en tanto que concebidos para uso privado. (Dorandi, 2007, p. 77).

72. En todo caso debería señalarse como ['Iatpıká]. (Ricciardetto, 2014, p. 41). Conviene precisar que lo que más se 
asemeja a un título en todo el papiro no se encuentra en el

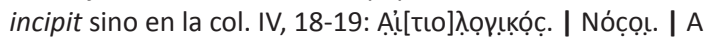
fin de evitar la "incómoda" denominación de 'título' digamos, en su lugar, que se cree que ambos términos figuran como el encabezamiento de la segunda sección del papiro. Quizá la voz más discordante en este asunto es la de M. Asper. Asper da una lectura diferente del encabezamiento:

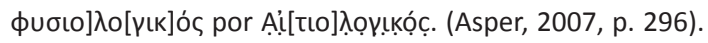
La escritura en esta parte del papiro es muy borrosa, casi ilegible, por lo que es muy difícil tomar parte en alguna de estas dos propuestas.

73. Menón sería llamado 'Aristóteles' en el Anonymus Londinensis. El escriba del Anónimo de Londres hace mención a Aristóteles en cols. V, 37; VI, 42; VII, [38], 43; XXIII, <42>; XXIV, 6. Cf. sed etiam cols. VII, [38]-40, 42-43; VIII, 10-12.

74. El autor del papiro desarrolla concretamente el pasaje que se encuentra en Aristóteles Somn.Vig. III 456b 26-457b 32, temática que se encuentra también en Aristóteles GA V 1 , 779a 5ss. La que transmite el Anonymus es, sino la primera, una de las primeras menciones al Somn.Vig. - y por lo demás también a otros tratados que conforman los Parva Naturalia de Aristóteles (especialmente Juv. IV 469b 7) después del proyecto editorial de Andrónico de Rodas.

75. Col. XXI, 18-47 donde el autor del papiro critica los criterios estequiológicos propuestos por Herófilo y Erasístrato. Las lineas 18-32 se encuentran recogidas en el fragmento 50a en (Staden von, 1989, p. 125).

76. De hecho la clasificación de los tejidos que hizo Aristóteles no se verá prácticamente modificada hasta finales del s. XVIII, con los trabajos de X. Bichat. (Musitelli, 1996, p. 234).

77. Aristóteles GA I 1, 715a 9-11; Cael. III 3, 302a 32.

78. ò como 'semejantes' o 'similares'. Cf. Aristóteles HA I 1, 486a 13-14; PA II 1, 646b 34-35. (von Staden, 1989, p. 536). En Aristóteles las partes homoiomerē corresponden a lo que la medicina actual tiene por tejidos estromáticos o estructurales (no parenquimáticos). Aristóteles concibió los huesos, los nervios, el tuétano, la piel y la carne como homoiomerē. En Aristóteles GC I 1, 314a 18-24 las llamadas partes homoiomerē proporcionan el material con el que Aristóteles cree que se forman los órganos pertenecientes a un sistema o un aparato concreto. Como tales las partes homeómeras están constituidas por lo seco y lo húmedo. Cf. Aristóteles Mete. IV 10, 388a 10-26.

79. Col. I, 24 pero especialmente, y a efectos prácticos, col. II, 9. Después de haber realizado un examen autóptico del pasaje y de haberlo releído por medio de imágenes digitales de alta resolución (por lo que quiero expresar mi sincera gratitud a la directora del CeDoPaL de la Université de Liège, la Prof. M. -H. Marganne, y al Dr. A. Ricciardetto) no hay duda de que, en lugar de 'endelécheia' (o 'entelécheia'), lo que se encuentra escrito en el papiro es 'entrécheia'. La primera aparición del término en- trécheia se encuentra entre dobles corchetes, es decir, inserto en medio del largo pasaje de la primera columna que el mismo escriba borró. Por contra, esto no se da en la segunda ocasión en que el autor escribe el término, por lo que hay que suponer que el escriba era

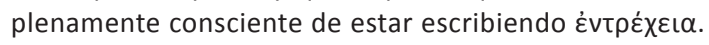
Según Diels se trata de un error debido simplemente a las pocas luces y a la ignorancia del escriba. (Diels, 1893, pp. XV, 90). Desde otra perspectiva, pero con el mismo objetivo, esta opinión es compartida por P. Podolak. Podolak descarta la hipótesis de que el papiro pudiera haber sido escrito por el médico Sorano de Efeso (tal y como M. Wellmann en principio postuló) porque la supuesta deformación léxica de entelécheia a entrécheia de ningún modo podría atribuírsele, pues Podolak cree que Sorano conocía las obras de Aristóteles - y el De anima en particular - a la perfección, y que a causa de esto nunca podría haber cometido semejante error. (Podolak, 2010, pp. 99-102). Lo más curioso del caso es que a juzgar por el contexto inmediato diríase que el significado que toma 'entrécheia' en el Anonymus es el de 'instinto', o incluso 'impulsividad'; justo el contrario del que cabría esperar.

80. La sección doxográfica del Anonymus Londinensis no sería solo el producto de una lectura del latriká por parte del escriba, sino que es un collage hecho a partir de diversas partes de otros tratados. (Manetti, 1996, p. 295).

81. No puede obviarse no obstante que Platón es, y de lejos, el autor más extensamente tratado en la segunda sección del papiro. (Lloyd, 2003, p. 152).

82. Cols. IV, 20-XIV, 11. Parece que una tal teoría nosológica se debe a Eurifonte de Cnido (ca. s. V a.C.). Cf. Col. IV, 31-40. (Nutton, 2004, p. 73).

83. Cols. IV, 18-XXI, 8.

84. En contraste con lo que ocurre con el término 'plēthos/ plēthora' de uso mucho más extendido. Cf. cols. V, 39; VII, 27, 34; VIII, 39; IX, 15; XII, 14; XIII, 22, 23, 25, 45; XIV, 4; XVII, 9. De acuerdo con el testimonio de Galeno en De usu part. VII 8 (III pp. 537-539 K.). Erasístrato consideró la plēthora como una superfluidad sanguínea generada por la ingesta excesiva de alimento y, en consecuencia, como un principio patológico. Sostuvo que las condiciones mórbicas eran generalmente atribuibles a un exceso de sangre (hiperhemia) en las venas que hacía que esa se trasvasara en demasía desde la venas hacia las arterias a través de los finos capilares que en condiciones normales permanecen cerrados. Con esto también el suministro normal de pneūma a través de las arterias. (Staden von, 1989, 304; Longrigg, 1993, p. 217).

85. Aristóteles I 18, 724b 26-28.

86. En Aristóteles $H A X 1,634 \mathrm{~b}$ 9, por ejemplo, por períttōma se entiende 'secreción vaginal'. Hay que recordar que Aristóteles no parece distinguir entre esperma masculino y esperma femenino, o mejor, usa el mismo término para 
designar tanto el esperma masculino como el fluido vaginal femenino. Aristóteles $H A \times 2,634 \mathrm{~b} 32$. (Eijk van der, 2005, p. 270).

\section{Aristóteles $H A X \times 5,637$ a 40-41.}

88. Cf. Aristóteles Mete. IV 6, 383a 6-9.

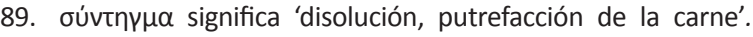
(Thivel, 2001, p. 204). En el Anonymi medici XXVI 3, 12, 16 el

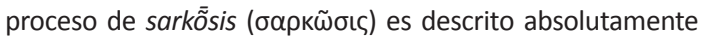
de otro modo modo, a saber, como un ejercicio por medio del cual se busca aumentar la masa muscular. El así llamado Anonymi medici (también Anonymus Parisinus o P. suppl. gr. 636) es un manuscrito griego del s. XVI conservado en la Gallerie Mazarie, Bibliothèque Nationale de France (BnF). Las páginas $21 r-82 r$ de dicho manuscrito contienen una obra médica del s. I d.C. (coetánea por tanto al papiro Anónimo de Londres) titulada De morbis acutis et chroniis, cuya edición estuvo a cargo de I. Garofalo en 1997. (Garofalo, 1992, pp. 92-93, 95). En el Anonymus Parisinus cada uno de los cuatro médicos principales que se citan explica una misma enfermedad por recurso a un proceso particular. Así, la ekchylōsis es la que caracteriza a Hipócrates, la émphraxis a Diocles, la sēpsis a Praxágoras y la paremptōsis a Erasístrato (Eijk van der, 1999, p. 313).

90. A. Thivel opina que la explicación de la enfermedad por recurso a la noción de períttōma no puede ser aristotélica. Dónde está aquí el error por parte del escriba? Thivel cree que todo es cuestión de las Aréskonta de Alejandro Philalethes, recopilación de la que el autor del papiro pudo haberse servido y de donde obtuvo una versión equivocada de las doctrinas de Aristóteles. (Thivel, 2001, pp. 204-205).

91. Aristóteles PA II, 1 646a 8-30; GA I 18, 722a 15-b 4. (Vegetti, 1984, p. 443; Viano, 1984, 319-320).

92. Aristóteles Mete. IV 3, 380a 8; Pseudo Aristóteles Pr. I 17, 861a 23. Podría decirse que la fisiología aristotélica está basada en una termodinámica fundamental. (Horne, 1963, p. 322). Aristóteles distinguió tres tipos de 'cocción', es decir, de posibles efectos del calor sobre la materia. Entre estos, la putrefacción era siempre consecuencia de un calor desproporcionado. Aristóteles Mete. IV 1, 379a 14-15.

93. El término pếpsis (digestión) se encuentra vinculado al de sếpsis (putrefacción) pero con el tiempo este último tomará un sentido estrictamente nosológico, a saber, el del proceso que lleva consigo un calor excesivo. (Steckerl, 1958, p. 32). Cf. Aristóteles Mete. IV 1, 379a 14-15; 3, 381b 7-8. Quizá sea por eso que Empédocles concibió la digestión más como una putrefacción que como una cocción. (Longrigg, 1993, pp. 162, 172). Mientras que la digestión se da en las partes altas de las vísceras, las heces se generan en las partes bajas (puesto que es allí donde los residuos se acumulan y es por ende más probable que se dé un proceso de putrefacción). Col. XVI, 19-24. Cf. Aristóteles Mete. IV 3, 381b 10-14; HA V 19, 551a 4-8. En la literatura médica producida en el Liceo el verbo péttesthai se emplea a veces para hacer referencia al estado de maduración o a la completa absorción de los humores nocivos del cuerpo como si de la cocción de un guiso se tratara, por ejemplo en Pseudo Aristóteles Pr. 16, 859b 13 (Marenghi, 1965, pp. 27-29 n. 18). En Aristóteles $H A X 7,638 b 4$ se emplea la forma verbal pépsai para describir la cocción que tiene lugar en el interior de la matriz, su autor compara por tanto la gestación con una cocción.

94. Aristóteles PA II 3, 650a 4-5.

95. Aristóteles Mete. IV 3, 381b 7-8. Quizá exceptuando el caso de Erasístrato, para quien la digestión era el resultado de una trituración que experimentaba el alimento en el estómago antes de ser absorbido como quilo en los vasos comunicantes con el hígado, dando por tanto una explicación más bien mecanicista del asunto; la gran mayoría de las antiguas teorías griegas sobre la digestión pretendieron dar razón de la transformación de los alimentos en sangre por medio de un proceso similar a la cocción o a la ebullición. Cf. Platón Ti. 80d ss.; Aristóteles PA III 7, 670a 20-b 31. (Staden von, 1989, pp. 265-266; Longrigg, 1993, p. 215; Byl, 2011b, p. 24).

96. Puesto que no se encuentra en el Corpus hippocraticum debemos pensar que Aristóteles acuñó el término 'anathymíasis' para describir precisamente un tal proceso - del que también dirá ser la causa del sueño. (Debru, 1996, p. 189 n. 46; Eijk van der, 2005, p. 142).

97. Aristóteles Juv. III 469a 1-2. Para Aristóteles todos los seres vivos tienen sangre o algún líquido análogo.

98. Cuando se examina su antónimo, apepsía, vemos que en general significa 'crudeza, indigestión, privación o ausencia de cocción, alimento que no se ha transformado en jugo'. Cuando se trata de la corrupción de la cocción entonces se usa el término 'dispepsía'. Se podría decir que todo el primer grupo de médicos descritos en la segunda sección del Anonymus parten del convencimiento de que las enfermedades se dan por algún tipo de disfunción digestiva, normalmente desencadenada por una desproporción entre el calor en el cuerpo y la cantidad de comida ingerida, cosa que genera residuos (períttōmata) que hacen enfermar. (Tacchini, 1996, p. 98).

99. Aristóteles Mete. II 8, 366b 25-30. Fue también Diocles quien prestó mayor atención al bloqueo del aire del interior del cuerpo como causa eficiente de un gran número de trastornos. Así, si el pneūma era bloquedo por la flema en la aorta eso podía provocar epilepsia o apoplegía. La obstrucción del pneūma en el cuerpo podía desencadenar fiebres, cefaleas, o incluso melancolía si dicha obstrucción se daba en el corazón. (Nutton, 2004, pp. 121-122, 126).

100. Aristóteles Sens. V, 444a 10-15.

101. Aristóteles Somn. Vig. III, 461a 23-25.

102. En los tiempos de Aristóteles, o inmediatamente posteriores, por 'satirismo' se entendía una deformación de las facciones del rostro mientras que más adelante, por lo menos 
a partir del s. I d.C. según puede leerse en el Anonymus Parisinus XVI 1-2, 15-23, el satirismo será la inflamación de los conductos seminales o del cuello de la vejiga, inflamación que acarreaba un fuerte deseo sexual acompañado de fuertes dolores en la zona genital y de episodios delirantes. Cf. Anonymi medici XVI 1-2.

103. Aristóteles GA IV 3, 768b 34-36; V 6, 786a 6-21.

104. D. Gourevitch y J. Longrigg creen que el médico Filistión de Locris (cols. XX, 25-XXI, 8 [?]) es el más claro precursor de las teorías médicas de Aristóteles. (Gourevitch, 1989, pp. 237-239; Longrigg, 1993, p. 158). Filistión fue un médico siciliano del s.V a.C., a quien Platón cita en la Carta II 314e (Bidez y Leboucq, 1944, pp. 7, 17-18; Nutton, 2004, p. 115). Junto a Filolao de Crotona y a Menécrates de Siracusa es uno de los tres médicos del sur de Italia que atribuyen las causas de la enfermedad a una desproporción entre los elementos constituyentes del cuerpo y sus cualidades. Hipón de Crotona y Timoteo de Metaponto, los otros dos suritalianos mencionados en el papiro, atribuyen en cambio las enfermedades a los residuos generados por los alimentos.

105. En relación a esto son significativos los pasajes de las cols. VI, 42-44 y VII, 37-40 del Anonymus Londinensis pues enmarcan la que el autor del papiro cree ser la verdadera doctrina de Hipócrates acerca de las causas de la enfermedad. Para ello en ambos pasajes el escriba insiste en que hay que diferenciar lo que Aristóteles creía que Hipócrates pensaba acerca de las causas de la enfermedad de lo que Hipócrates en realidad pensaba del asunto.

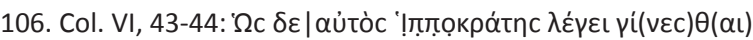
tàc vóco(uc), es decir, como el mismo Hipócrates afirma las enfermedades se originan...

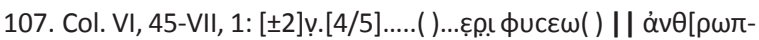

108. (Giannantoni, 1984, p. 49; Manetti, 1986, p. 63 n. 26; Thivel, 2001, p. 207; Nutton, 2004, pp. 59-60; Byl, 2011a, p.

\section{EDICIONES DE OBRAS DE AUTORES ANTIGUOS}

Aelio, Varia Historia. En: Herscher, Rudolph (ed.), De animalium natura (libri XVII) vol. II: Varia Historia. Epistolae. Fragmenta, Leipzig, Biblioteca Teubneriana, 1886, pp. 95-107.

Alejandro de Afrodisia, In librum De sensu commentarium. En: Wendland, Paul (ed.), Commentaria in Aristotelem Graeca vol. III, 1, Berlín, Academiae Litterarum Regiae Borussicae, 1901.

Anonymi medici: De morbis acutis et chroniis, Garofalo, Ivan (ed.), Leiden-Nueva York, E. J. Brill, 1997. $=($ Anonymi medici $)$

Aristóteles, Eudemian Ethics. En: Page, Thomas Ethelbert; Capps, Edward; Rouse, William Henry Denham; Post, Levi
242; Byl, 2011b, p. 93; Manetti, 2014, p. 233 n. 12). Las opiniones de Pólibo acerca de las causas de la enfermedad se encuentran también recogidas en la col. XIX, 2-18. EI Anonymus recoge una versión resumida de los capítulos 3-4 del de Nat. hom. de Hipócrates. En HA III 3, 512b 12513a 7 Aristóteles da una descripción de los vasos sanguíneos y para ello cita extensamente a Pólibo. (Ricciardetto, 2014, pp. XLIV n. 278; Eijk van der, 2014, pp. 348-349).

109. Col. VII, 18-21.

110. Por lo general 'visita, notas de viaje tomadas por un médico, llegada esporádica a un cierto lugar...' (Pino y Hernández, 2008, pp. 200-201).

111. Hipócrates Nat. hom. IX (VI pp. 52, 14-54, 4 Li.). Otro uso similar se da en Hipócrates Progn. XXV (II p. 188, 12-14 Li). (Laín Entralgo, 1982, p. 226).

112. Aristóteles no fue un 'practitioner' sino un 'physician'.

113. (Gourevitch, 1989, p. 247). El modo en que Aristóteles concibió la salud parece estar en correspondencia con el formulado por Alcmeón de Crotona. (Diels, 1903, p. 107 fr. $442 \mathrm{D})$.

114. Aristóteles EN II 2, 1104a 14-18.

115. Aristóteles Ph. VII 3, 246b 4-6; Top. VI 2, 139b 20-21.

116. (Nutton, 2004, pp. 96-97; Byl, 2011a, p. 248). La distinción médica fundamental entre terapia alopática y homeopática podría tener sus fundamentos en las doctrinas de Empédocles. Tal y como se expone en Hipócrates Flat I 4-5 ó en Vet. med. XIII, los principios de la cura alopática son una característica distintiva de la medicina racionalista o dogmática. (Eijk van der, 2014, pp. 353, 360).

117. Aristóteles EE || 1, 1220a 35-37; EN || 2, 1104b 16-18; VII 15, 1154a 25-31.

Arnold; Warmington, Eric Herbert (eds.), The Athenian Constitution. The Eudemian Ethics. On Virtues and Vices, Cambridge (MA)-Londres, Biblioteca Clásica Loeb, 1961, pp. 198-477. $=(E E)$

Aristóteles, Generation of Animals, Page, Thomas Ethelbert; Capps, Edward; Rouse, William Henry Denham; Post, Levi Arnold; Warmington, Eric Herbert (eds.), Cambridge (MA)Londres, Biblioteca Clásica Loeb, 1953. = (GA)

Aristóteles, Historia Animalium in Three Volumes (Books I-III) vol. I, Page, Thomas Ethelbert; Capps, Edward; Rouse, William Henry Denham; Post, Levi Arnold; Warmington, Eric 
Herbert (eds.), Cambridge (MA)-Londres, Biblioteca Clásica Loeb, 1965. = $(H A)$

Aristóteles, Metaphysics (Books 1-9) vol. I, Page, Thomas EtheIbert; Capps, Edward; Rouse, William Henry Denham; Post, Levi Arnold; Warmington, Eric Herbert (eds.), Cambridge (MA)-Londres, Biblioteca Clásica Loeb, 1933. = (Metaph.)

Aristóteles, Metereologica, Page, Thomas Ethelbert; Capps, Edward; Rouse, William Henry Denham; Post, Levi Arnold; Warmington, Eric Herbert (eds.), Cambridge (MA)-Londres, Biblioteca Clásica Loeb, 1952. = $($ Mete.$)$

Aristóteles, On Coming-To-Be and Passing Away. En: Page, Thomas Ethelbert; Capps, Edward; Rouse, William Henry Denham; Post, Levi Arnold; Warmington, Eric Herbert (eds.), On Sophistical Refutations. On Coming-To-Be and Passing Away. On the Cosmos, Cambridge (MA)-Londres Biblioteca Clásica Loeb, 1965, pp. 162-329. = (GC)

Aristóteles, On Length and Shortness of Life. En: Page, Thomas Ethelbert; Capps, Edward; Rouse, William Henry Denham; Post, Levi Arnold; Warmington, Eric Herbert (eds.), On the Soul. Parva Naturalia. On Breath, Cambridge (MA)-Londres, Biblioteca Clásica Loeb, 1957, pp. 394-409. = (Long.)

Aristóteles, On Respiration. En: Page, Thomas Ethelbert; Capps, Edward; Rouse, William Henry Denham; Post, Levi Arnold; Warmington, Eric Herbert (eds.), On the Soul. Parva Naturalia. On Breath, Cambridge (MA)-Londres, Biblioteca Clásica Loeb, 1957, pp. 430-481. = (Resp. $)$

Aristóteles, On Sense and Sensible Objects. En: Page, Thomas Ethelbert; Capps, Edward; Rouse, William Henry Denham; Post, Levi Arnold; Warmington, Eric Herbert (eds.), On the Soul. Parva Naturalia. On Breath, Cambridge (MA)-Londres, Biblioteca Clásica Loeb, 1957, pp. 214-283. = (Sens.)

Aristóteles, On Sleep and Waking. En: Page, Thomas Ethelbert; Capps, Edward; Rouse, William Henry Denham; Post, Levi Arnold; Warmington, Eric Herbert (eds.), On the Soul. Parva Naturalia. On Breath, Cambridge (MA)-Londres, Biblioteca Clásica Loeb, 1957, pp. 318-345. = (Somn. Vig.)

Aristóteles, On the Cosmos. En: Page, Thomas Ethelbert; Capps, Edward; Rouse, William Henry Denham; Post, Levi Arnold; Warmington, Eric Herbert (eds.), On Sophistical Refutations. On Coming-To-Be and Passing Away. On the Cosmos, Cambridge (MA)-Londres, Biblioteca Clásica Loeb, 1965, pp. 344409. $=($ Cael. $)$

Aristóteles, On Youth and Old Age. En: Page, Thomas Ethelbert; Capps, Edward; Rouse, William Henry Denham; Post, Levi Arnold; Warmington, Eric Herbert (eds.), On the Soul. Parva Naturalia. On Breath, Cambridge (MA)-Londres, Biblioteca Clásica Loeb, 1957, pp. 412-427. = (Juv.)

Aristóteles, Parts of Animals. En: Page, Thomas Ethelbert; Capps, Edward; Rouse, William Henry Denham; Post, Levi Arnold; Warmington, Eric Herbert (eds.), Parts of Animals.
Movement of Animals. Progression of Animals, Cambridge (MA)-Londres, Biblioteca Clásica Loeb, 1961, pp. 52-434. $=(P A)$

Aristóteles, Politics, Page, Thomas Ethelbert; Capps, Edward; Rouse, William Henry Denham; Post, Levi Arnold; Warmington, Eric Herbert (eds.), Cambridge (MA)-Londres, Biblioteca Clásica Loeb, 1950. $=($ Pol. $)$

Aristóteles, The "Art" of Rhetoric, Page, Thomas Ethelbert; Capps, Edward; Rouse, William Henry Denham; Post, Levi Arnold; Warmington, Eric Herbert (eds.), Cambridge (MA)Londres, Biblioteca Clásica Loeb, 1947. $=(R h$.

Aristóteles, The Nichomachean Ethics, Page, Thomas Ethelbert; Capps, Edward; Rouse, William Henry Denham; Post, Levi Arnold; Warmington, Eric Herbert (eds.), Cambridge (MA)Londres, Biblioteca Clásica Loeb, 1962. = $(E N)$

Aristóteles, The Physics in Two Volumes (Books 1-4) vol. I, Page, Thomas Ethelbert; Capps, Edward; Rouse, William Henry Denham; Post, Levi Arnold; Warmington, Eric Herbert (eds.), Cambridge (MA)-Londres, Biblioteca Clásica Loeb, 1970. = (Ph.)

Aristóteles, The Physics in Two Volumes (Books 5-8) vol. II, Page, Thomas Ethelbert; Capps, Edward; Rouse, William Henry Denham; Post, Levi Arnold; Warmington, Eric Herbert (eds.), Cambridge (MA)-Londres, Biblioteca Clásica Loeb, 1934. = (Ph.)

Aristóteles, Topica. En: Page, Thomas Ethelbert; Capps, Edward; Rouse, William Henry Denham; Post, Levi Arnold; Warmington, Eric Herbert (eds.), Posterior Analytics. Topica, Cambridge (MA)-Londres, Biblioteca Clásica Loeb, 1960, pp. 272-740. $=($ Top. $)$

Pseudo Aristóteles, Problemi di medicina, Marenghi, Gerardo (ed.), Milán, Istituto editoriale italiano, 1965. = (Pr.)

Caelio Aureliano, Celerum passionum (libri I-III). En: Bendz, Gerhard (ed.), Corpus Medicorum Latinorum. Caeli Aureliani Celeri Passionum (libri III). Tardarum Passionum (libri I-II) vol. VI 1, 1, Berlín, Academiae Scientiarum, 1990, pp. 20-422.

Diógenes Laercio, Vitae philosophorum (libri I-IX) vol. I, Marcovich, Miroslav (ed.), Stuttgart-Leipzig, Biblioteca Teubneriana, 1999

Galeno, De anatomicis administrationibus (libri I-IX). En: Kühn, Carl Gottlob (ed.), Claudii Galeni Opera Omnia vol. II, Leipzig, Officina libraria Car. Cnoblochii, 1821, pp. 215-731. = (De anat. admin.)

Galeno, De methodo medendi (libri I-XIV). En: Kühn, Carl Gottlob (ed.), Claudii Galeni Opera Omnia vol. X, Leipzig, Officina libraria Car. Cnoblochii, 1825, pp. 1-1021. = (De meth. med .)

Galeno, De placitis Hippocratis et Platonis (libri I-IX). En: Kühn, Carl Gottlob (ed.), Claudii Galeni Opera Omnia vol. V, Leipzig, Officina libraria Car. Cnoblochii, 1823, pp. 181-805. = (De plac. Hipp. et Plat.) 
Galeno, De pulsuum differentiis (libri I-IV). En: Kühn, Carl Gottlob (ed.), Claudii Galeni Opera Omnia vol. VIII, Leipzig, Officina libraria Car. Cnoblochii, 1824, pp. 493-765. $=($ De diff. puls. $)$

Galeno, De usu partium corporis humani. En: Kühn, Carl Gottlob (ed.), Claudii Galeni Opera Omnia vol. III, Leipzig, Officina libraria Car. Cnoblochii, 1822, pp. 1-938. = (De usu part.)

Galeno, In Hippocratis de natura hominis commentarii II. En: Kühn, Carl Gottlob (ed.), Claudii Galeni Opera Omnia vol. XV, Leipzig, Officina libraria Car. Cnoblochii, 1828, pp. 1-173. = (In Hipp. Nat. Hom. comment.)

Hipócrates, De la nature de l'homme. En: Littré, Émile (ed.), CEuvres complètes d'Hippocrate vol. VI, París-Londres, J. B. Baillière, 1849, pp. 29-70. = (Nat. hom.)

Hipócrates, De la nature des os. En: Littré, Émile (ed.), CEuvres complètes d'Hippocrate vol. IX, París-Londres, J. B. Baillière, 1861, pp. 168-197. = (Oss.)

Hipócrates, De l'ancienne médecine. En: Littré, Émile (ed.), CEuvres complètes d'Hippocrate vol. I, París-Londres, J. B. BaiIlière, 1839, pp. 570-636. = (Vet. med.)

Hipócrates, Des lieux dans l'homme. En: Littré, Émile (ed.), CEuvres complètes d'Hippocrate vol. VI, París-Londres, J. B. BaiIlière, 1849, pp. 276-349. = (Loc. Hom.)

Hipócrates, Des maladies des femmes. En: Littré, Émile (ed.), CEuvres complètes d'Hippocrate vol. VIII, París-Londres, J. B. Baillière, 1853, pp. 10-407. $=($ Mul. $)$

Hipócrates, Des vents. En: Littré, Émile (ed.), CEuvres complètes d'Hippocrate vol. VI, París-Londres, J. B. Baillière, 1849, pp. 88-116. = (Flat. $)$

Hipócrates, Le pronostic. En: Littré, Émile (ed.), CEuvres complètes d'Hippocrate vol. II, París-Londres, J. B. Baillière, 1840, pp. 110-191. $=($ Progn.$)$

\section{BIBLIOGRAFÍA}

Allbutt, Thomas (1921), Greek Medicine in Rome, Londres, McMillan \& Co.

Andorlini, Isabella y Marcone, Arnaldo (2008), Medicina, medico e società nel mondo antico, Florencia, La Monnier Università.

Asper, Markus (2007), Griechische Wissenschaftstexte. Formen, Funktionen, Differenzierungsgeschichten, Stuttgart, F. Steiner.

Berger, Friederike (2005), Die Textgeschichte der Historia Animalium des Aristoteles, Wiesbaden, L. Reichert.

Bidez, Joseph (1943), Un Singulier Naufrage Littéraire dans I'Antiquité. A la recherche des Épaves de l'Aristote perdu, Bruselas, J. Lebègue \& Cie.
Oribasio, Collectionum medicarum reliquiae (libri XLIX-L) vol. IV. Libri incerti. Eclogae medicamentorum. Index. En: Raeder, Ioannes (ed.), Corpus Medicorum Graecorum VI 2, 2, Academia Berolinensis Havniensis Lipsiensis, Leipzig-Berlín, Biblioteca Teubneriana, 1933.

Platón, Charmides. En: Page, Thomas Ethelbert; Capps, Edward; Rouse, William Henry Denham; Post, Levi Arnold; Warmington, Eric Herbert (eds.), Plato with an English Translation vol. VIII: Charmides. Alcibiades I-II. Hipparchus. The Lovers. Theages. Minos. Epinomis, Cambridge (MA)-Londres, Biblioteca Clásica Loeb, 1927, pp. 1-92. = (Chrm.)

Platón, Laws. En: Page, Thomas Ethelbert; Capps, Edward; Rouse, William Henry Denham; Post, Levi Arnold; Warmington, Eric Herbert (eds.), Laws in Two Volumes (Books 1-6), Cambridge (MA)-Londres, Biblioteca Clásica Loeb, 1961. $=(\operatorname{Lg}$.

Platón, Laws. En: Page, Thomas Ethelbert; Capps, Edward; Rouse, William Henry Denham; Post, Levi Arnold; Warmington, Eric Herbert (eds.), Laws in Two Volumes (Books 7-12), Cambridge (MA)-Londres, Biblioteca Clásica Loeb, 1961. $=(L g$.

Platón, Protagoras. En: Page, Thomas Ethelbert; Capps, Edward; Rouse, William Henry Denham; Post, Levi Arnold; Warmington, Eric Herbert (eds.), Plato with an English Translation vol. II: Laches. Protagoras. Meno. Euthydemus, Cambridge (MA)-Londres, Biblioteca Clásica Loeb, 1962, pp. 92-257. $=($ Prt. $)$

Platón, Timaeus. En: Page, Thomas Ethelbert; Capps, Edward; Rouse, William Henry Denham; Post, Levi Arnold; Warmington, Eric Herbert (eds.), Plato with an English Translation vol. VII: Timaeus. Critias. Cleitophon. Menexenus. Epistles, Cambridge (MA)-Londres, Biblioteca Clásica Loeb, 1961, pp. 16-253. $=($ Ti. $)$

Bidez, Joseph y Leboucq, Georges (1944), “Une anatomie antique du cœur humain Philistion de Locres et le "Timée» de Platon", Revue des Études Grecques, 57, pp. 7-40.

Boudon, Véronique (1994), “Les œuvres de Galien pour les débutants ("De sectis", "De pulsibus ad tirones", "De ossibus ad tirones", "Ad Glauconem de methodo medendi" et "Ars medica"): médecine et pédagogie au II s. ap. J.- C". En: Haase, Wolfgang; Temporini, Hildegard (eds.), Aufstieg und Niedergang der Römische Welt (ANRW) II, 37, 2, Berlín-Nueva York, W. de Gruyter \& Co, pp. 1421-1467.

Byl, Simon (2011a), De la médecine magique et religieuse à la médecine rationnelle. Hippocrate, París, L’Harmattan. 
Byl, Simon (2011b), La médecine à l'époque hellénistique et romaine. Galien, París, L’Harmattan.

Daremberg, Charles y Ruelle, Charles-Émile (1879), œuvres de Rufus d'Éphèse, París, Imprimerie Nationale. Reimpresión anastática (1963), Amsterdam, A. M. Hakkert.

Debru, Armelle (1995), "Les démonstrations médicales à Rome au temps de Galien". En: Eijk, Philip Jan van der; Horstmanshoff, Herman; Schrijvers, Peter (eds.), Ancient Medicine in its SocioCultural Context. Papers Read at the Congress Held at Leiden University 13-15 April 1992, I, Amsterdam, Rodopi, pp. 69-81.

Debru, Armelle (1996), Le corps respirant. La pensée physiologique chez Galien, Leiden-Nueva York-Colonia, E. J. Brill.

Diels, Hermann (1893), Anonymi Londiniensis ex Aristotelis Iatriciis Menoniis et aliis medicis Eclogae. En: Diels, Hermann; Academiae Litterarum Regiae Borussicae (eds.), Supplemetum Aristotelicum III, 1 Berlín, G. Reimer, pp. 1-74.

Diels, Hermann (1903), Die Fragmente der Vorsokratiker, Berlín, Weidmannsche Buchhandlung.

Dorandi, Tiziano (2007), Nell'officina dei classici. Come lavoravano gli autori antichi, Roma, Carocci.

Drabkin, Israel (1944), “On Medical Education in Greece and Rome", Bulletin of the History of Medicine, 15, pp. 333-351.

Eijk, Philip Jan van der (1995), "Aristotle on "Distinguished Physicians" and on the Medical Significance of Dreams". En: Eijk, Philip Jan van der; Horstmanshoff, Herman; Schrijvers, Peter (eds.), Ancient Medicine in its Socio-Cultural Context. Papers Read at the Congress Held at Leiden University 13-15 April 1992, I, Amsterdam, Rodopi, pp. 447-459.

Eijk, Philip Jan van der (1999), "The Anonymus Parisinus and the Doctrines of "the Ancients" ". En: Eijk, Philip Jan van der (eds.), Ancient Histories of Medicine. Essays in Medical Doxography and Historiography in Classical Antiquity, Leiden-Boston-Colonia, Brill, pp. 295-331.

Eijk, Philip Jan van der (2005), Medicine and Philosophy in Classical Antiquity, Cambridge, Cambridge University Press.

Eijk, Philip Jan van der (2014), "Hippocrate aristotélicien”. En: Jouanna, Jacques; Zink, Michel (eds.), Hippocrate et les hippocratismes : médecine, religion, société. Actes du XIVe Colloque International Hippocratique à la Maison de la Recherche, à l'Académie des Inscriptions et Belles-Lettres et à la Bibliothèque Interuniversitaire de Santé, les 8, 9 et 10 novembre 2012, París, Académie des Inscriptions et Belles Lettres, pp. 347-369.

Eijk, Philip Jan van der y Francis, Sarah (2009), "Aristoteles, Aristotelismus und antique Medizin". En: Brockmann, Christian; Brunschön, Wolfram; Overwien, Oliver (eds.), Antike Medizin im Schnittpunkt von Geistes - und Natur Wissenschaften, Berlín-Nueva York, W. de Gruyter, pp. 213-233.
French, Roger (2000), "Where the Philosopher Finishes, the Physician Begins: Medicine and the Arts Course in Thirteenth Century Oxford", Dynamis. Acta Hispanica ad Medicinae Scientiarumque Historiam Illustrandam, 20, pp. 75-106.

Garofalo, Ivan (1992), "Prolegomena all'edizione dell'Anonymus Parisinus Darembergii sive Fuchsii". En: D’Auria, Maria (eds.), Tradizione e ecdotica dei testi medici tardoantichi e bizantini. Atti del Convegno Internazionale Anacapri 29-31 ottobre, Nápoles, M. D’Auria, pp. 91-106.

Giannantoni, Gabriele (1984), "Su alcuni problemi circa i raporti tra scienza e filosofia nell'età ellenistica". En: La scienza ellenistica. Atti delle tre giornate di studio tenutesi a Pavia dal 14 al 16 Aprile 1982, Pavia, Bibliopolis, pp. 39-73.

Gigon, Olof (1987), Aristotelis Opera III. Librorum Deperditorum Fragmenta, Berlín-Nueva York, Walter de Gruyter.

Gourevitch, Danielle (1989), "L'Anonyme de Londres et la médecine d'Italie du Sud", History and Philosophy of the Life Sciences, 11, pp. 237-251.

Graham, Daniel (2010), The Texts of Early Greek Philosophy I, Cambridge, Cambridge University Press.

Grmek, Mirko (1997), Le chaudron de Médée. L'expérimentation sur le vivant dans l'Antiquité, Le Plessis-Robinson, Institut Synthélabo pour le progrès de la connaissance.

Heitz, Emil (1865), Die Verlorenen Schriften des Aristoteles, Leipzig, Bibliotheca Teubneriana.

Hirt Raj, Marguerite (2006), Médecins et malades de l'Égypte Romaine, Leiden-Boston, Brill.

Horne, Ralph (1963), "Atomism in Ancient Medical History", Medical History, 7, pp. 317-329.

Horstmanshoff, Herman (1990), "The Ancient Physician: Craftsman or Scientist?", Journal of the History of Medicine and Allied Sciences, 45, pp. 176-197.

Jaeger, Werner (1945), Paideia: the Ideals of Greek Culture III, Oxford, Basil Blackwell.

Jori, Alberto (1995), "Le pepaideumenos et la médecine”. En: Eijk, Philip Jan van der; Horstmanshof, Herman; Schrijvers, Peter (eds.), Ancient Medicine in its Socio-Cultural Context. Papers read at the Congress held at Leiden University 13-15 April 1992 II, Amsterdam, Rodopi, pp. 411-424.

Kenyon, Frederic (1892), "A Medical Papyrus in the British Museum", Classical Review, 6, pp. 237-240.

Kudlien, Fridolf (1963), "Probleme um Diokles von Karystos", Sudhoffs Archiv für Geschichte der Medizin und der $\mathrm{Na}$ turwissenschaften, 47, pp. 456-464.

Laín Entralgo, Pedro (1981), “Los orígenes del diagnóstico médico", Dynamis. Acta Hispanica ad Medicinae Scientiarumque Historiam Illustrandam, 1, pp. 3-15. 
Laín Entralgo, Pedro (1982), La medicina hipocrática, Madrid, Alianza.

Lee Too, Yun (2010), The Idea of the Library in the Ancient World, Oxford, Oxford University Press.

Lloyd, Geoffrey (1968), "The Role of Medical and Biological Analogies in Aristotle's Ethics", Phronesis, 13, pp. 68-83.

Lloyd, Geoffrey (2003), In the Grip of Disease. Studies in the Greek Imagination, Oxford, Oxford University Press.

Longrigg, James (1993), Greek Rational Medicine. Philosophy and Medicine from Alcmeon to the Alexandrians, LondresNueva York, Routledge.

Longrigg, James (1995), "Medicine and the Lyceum”. En: Eijk, Philip Jan van der; Horstmanshoff, Herman; Schrijvers, Peter (eds.), Ancient Medicine in its Socio-Cultural Context. Papers read at the Congress held at Leiden University 13-15 April 1992 II, Amsterdam, Rodopi, pp. 431-445.

Manetti, Daniela (1986), "Note di lettura dell'Anonimo Londinense. Prolegomena ad una nuova edizione", Zeitschrift für Papyrologie und Epigraphik, 63, pp. 57-74.

Manetti, Daniella (1989), "latrica sive Collectio medica". En: Olschki, Leo (eds.), Corpus dei papiri filosofici greci e latini. Parte I Autori Noti vol I, Florencia, L. S. Olschki, pp. 345-351.

Manetti, Daniela (1990), "Doxographical deformation of medical tradition in the report of the Anonymus Londiniensis on Philolaus", Zeitschrift für Papyrologie und Epigraphik, 83, pp. 219-233.

Manetti, Daniela (1994), "Autografi e incompiuti: il caso dell'Anonimo Londinense P. Lit. Lond. 165". Zeitschrift für Papyrologie und Epigraphik, 100, pp. 47-58.

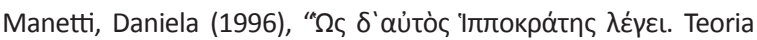
causale e ippocratismo nell'Anonimo Londinese (VI 43ss.)". En: Wittern, Renate; Pellegrin, Pierre (eds.), Medizin der Antike. Hippokratische Medizin und antike Philosophie. Verhandlungen des VIII. International Hippokrates-Kolloquiums in Kloster Banz/Staffelstein vom 23. bis 28. September 1993 vol. I, Hildesheim-Zürich-Nueva York, Olms Weidmann, pp. 295-310.

Manetti, Daniela (1999a), " "Aristotle" and the role of doxography in the Anonymus Londiniensis (PBrLibr inv.137)". En: Eijk, Philip Jan van der (eds.), Ancient Histories of Medicine. Essays in medical doxography and historiography in Classical Antiquity, Leiden-Boston-Colonia, Brill, pp. 95-143.

Manetti, Daniella (1999b), “Timaeus 42e; 73b-84e". En: Olschki, Leo (eds.), Corpus dei papiri filosofici greci e latini. Testi e lessico nei papiri di cultura greca e latina, Parte I Autori Noti vol 1*** (Platonis Testimonia - Zeno Tarsensis), Florencia, L. S. Olschki, pp. 528-578.

Manetti, Daniela (2005), "Medici contemporanei a Ippocrate: problemi di identificazione dei medici di nome Erodico". En:
Eijk, Philip Jan van der (eds.), Hippocrates in Context. Papers Read at the XIth International Hippocrates Colloquium University of Newcastle upon Tyne 27-31 August 2002, LeidenBoston, Brill, pp. 287-313.

Manetti, Daniela (2011), Anonymus Londiniensis: De Medicina, Berlín, Biblioteca Teubneriana.

Manetti, Daniela (2014), "Alle origini dell'Ippocratismo: fra IV e III sec". En: Jouanna, Jacques; Zink, Michel (eds.), Hippocrate et les hippocratismes: médecine, religion, société. Actes du XIV CoIloque International Hippocratique à la Maison de la Recherche, à l'Académie des Inscriptions et Belles-Lettres et à la Bibliothèque Interuniversitaire de Santé, les 8, 9 et 10 novembre 2012, París, Académie des Inscriptions et Belles Lettres, pp. 231-251.

Marcone, Arnaldo (2006), "Si può parlare di medicina tardoantica?". En: Medicina e società nel mondo antico. Atti del convegno di Udine (4-5 Ottobre 2005), Florencia, Le Monnier Università, pp. 266-284.

Marenghi, Gerardo (1961), "Aristotele e la medicina greca", Istituto Lombardo. Accademia di Scienze e Lettere, 95, pp. 141-161.

Marenghi, Gerardo (1965), Problemi di medicina, Milán, Istituto editoriale italiano.

Marganne, Marie-Hélène (2004), "Le livre médical dans le monde gréco-romain", Cahiers du CeDoPaL, 3, pp. 1-175.

Marganne, Marie-Hélène (2009), "La transmission du savoir médical dans le monde gréco-romain: l'apport de la papirologie". En: Le Blay, Frédéric (eds.), Transmettre les savoirs dans les mondes hellénistique et romain, Rennes, Presses Universitaires de Rennes, pp. 259-274.

Moraux, Paul (1951), Les listes anciennes des ouvrages d'Aristote, Lovaina, Éditions Universitaires.

Musitelli, S. (1996), "Pagine di odontoiatria e di odontologia nel mondo antico", Medicina nei secoli. Arte e scienza, 8 (2), pp. 207-235.

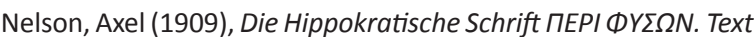
und studien, Uppsala, Almqvist \& Wiksells Buchdruckerei.

Nutton, Vivian (1995), "The Medical Meeting Place”. En: Eijk, Philip Jan van der; H. F. J Horstmanshof, Herman; Schrijvers, Peter (eds.), Ancient Medicine in its Socio-Cultural Context. Papers Read at the Congress Held at Leiden University 13-15 April 1992 I, Amsterdam, Rodopi, pp. 3-25.

Nutton, Vivian (2004), Ancient Medicine, Londres-Nueva York, Routledge.

Perilli, Lorenzo (2006), "Asclepio e Ippocrate, una fruttuosa collaborazione". En: Medicina e società nel mondo antico. Atti del convegno di Udine (4-5 Ottobre 2005), Florencia, Le Monnier Università, pp. 26-54 
Pino Campos, Luís Miguel y Hernández González, Justo Pedro (2008), "En torno al significado original del vocablo griego epidēmía y su identificación con el latino pestis", Dynamis. Acta Hispanica ad Medicinae Scientiarumque Historiam Illustrandam, 28, pp. 199-215.

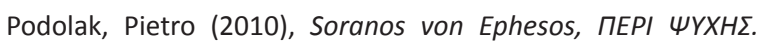
Sammlung der Testimonien, Kommentar und Einleitung, Berlín-Nueva York, De Gruyter.

Raeder, Hans (1931), “Menon”. En: Kroll, Wilhelm. (eds.), RE XV, 1, Stuttgart, A. Druckenmüller, p. 927.

Repici, Luciana (2006), "Medici e botanica popolare". En: Medicina e società nel mondo antico. Atti del convegno di Udine (4-5 Ottobre 2005), Florencia, Le Monnier Università, pp. 72-90.

Ricciardetto, Antonio (2014), L'Anonyme de Londres. Édition et traduction d'un papyrus médical grec du ler siècle, Lieja, Presses Universitaires de Liège.

Staden, Heinrich von (1975), "Experiment and Experience in Hellenistic Medicine", Bulletin of the Institute of Classical Studies, 22, 178-199.

Staden, Heinrich von (1989), Herophilus, The Art of Medicine in Early Alexandria, Cambridge, Cambridge University Press.

Steckerl, Fritz (1958), The Fragments of Praxagoras of Cos and his School, Leiden, E. J. Brill.

Tacchini, Isabella (1996), "Pepsis: ricerche intorno all'utilizzazione di un modello esplicativo". En: Studi di Storia della Medicina antica e medievale in memoria di Paola Manuli, Florencia, La Nuova Italia, pp. 88-100.

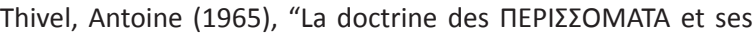
parallèles hippocratiques", Revue de Philologie, de Litterature et d'Histoire Anciennes, 39, pp. 266-282.

Thivel, Antoine (2001), "La doctrine d'Hippocrate dans l'Anonyme de Londres". En: Woronoff, Michel; Follet, Simone; Jouanna, Jacques (eds.), Dieux, héros et médicins grecs. Hommage à Fernand Robert, Besançon, Institut des Sciences et Techniques de l'Antiquité, pp. 197-209.

Vegetti, Mario (1984), "La scienza ellenistica: problemi di epistemologia storica". En: La scienza ellenistica. Atti delle tre giornate di studio tenutesi a Pavia dal 14 al 16 Aprile 1982, Pavia, Bibliopolis, pp. 427-470.

Viano, Carlo Augusto (1984), "Perché non c'era sangue nelle arterie? La cecità epistemologica degli anatomisti antichi". En: La scienza ellenistica. Atti delle tre giornate di studio tenutesi a Pavia dal 14 al 16 Aprile 1982, Bibliopolis, Pavia 1984, pp. 297-352.

Wellmann, Max (1922), “Der Verfasser des Anonymus Londiniensis", Hermes, 57, pp. 396-429.

Withington, Edward (1929), "Medicine: The IATPIKA of Menon. Anonymi Londiniensis latrica". En: Powell, John; Barber, Eric (eds.), New Chapters in the History of Greek Literature. Second Series, Oxford, Clarendon Press, 183-188.

Wilson, Leonard (1959), "Erasistratus, Galen and the Pneuma", Bulletin of the History of Medicine, 33, pp. 293-314.

Zeller, Eduard (1879), Die Philosophie der Griechen in ihner Geschichtlichen Entwicklung III, 2, Leipzig, Fues's Verlag. 